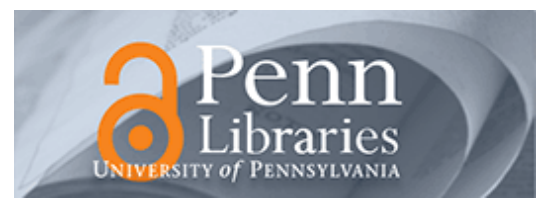

University of Pennsylvania

ScholarlyCommons

Health Care Management Papers

Wharton Faculty Research

$1-2004$

\title{
Reference Pricing of Pharmaceuticals for Medicare: Evidence From Germany, the Netherlands, and New Zealand
}

Patricia. M. Danzon

University of Pennsylvania

Jonathan. D. Ketcham

Follow this and additional works at: https://repository.upenn.edu/hcmg_papers

Part of the Insurance Commons, Medical Education Commons, Other Business Commons, Pharmacoeconomics and Pharmaceutical Economics Commons, and the Pharmacy Administration, Policy and Regulation Commons

\section{Recommended Citation}

Danzon, P. M., \& Ketcham, J. D. (2004). Reference Pricing of Pharmaceuticals for Medicare: Evidence From Germany, the Netherlands, and New Zealand. Forum for Health Economics \& Policy, 7 (1), 1-54. http://dx.doi.org/10.2202/1558-9544.1050

This paper is posted at ScholarlyCommons. https://repository.upenn.edu/hcmg_papers/138

For more information, please contact repository@pobox.upenn.edu. 


\title{
Reference Pricing of Pharmaceuticals for Medicare: Evidence From Germany, the Netherlands, and New Zealand
}

\author{
Abstract \\ This paper describes three prototypical systems of therapeutic reference pricing (RP) for \\ pharmaceuticals-Germany, the Netherlands, and New Zealand-and examines their effects on the \\ availability of new drugs, reimbursement levels, manufacturer prices, and out-of-pocket sur-charges to \\ patients. RP for pharmaceuticals is not simply analogous to a defined contribution approach to \\ subsidizing insurance coverage. Although a major purpose of RPis to stimulate competition, theory \\ suggests that the achievement of this goal is unlikely, and this is confirmed by the empirical evidence. \\ Other effects of RPdiffer across countries in predictable ways, reflecting each country's system design \\ and other cost-control policies. New Zealand's RPsystem has reduced reimbursement and limited the \\ availability of new drugs, particularly more expensive drugs. Compared to these three countries, if RP \\ were applied in the United States, it would likely have a more negative effect on prices of on-patent \\ products because of the more competitive U.S. generic market, and on research and development (R\&D) \\ and the future supply of new drugs, because of the much larger U.S. share of global pharmaceutical \\ sales.

\section{Disciplines} \\ Insurance | Medical Education | Other Business | Pharmacoeconomics and Pharmaceutical Economics | \\ Pharmacy Administration, Policy and Regulation
}




\section{Forum for Health Economics \& Policy}

Volume 7

2004

Article 2

(Frontiers in Health Policy Research)

Reference Pricing of Pharmaceuticals for

Medicare: Evidence from Germany, the

Netherlands, and New Zealand

Patricia M. Danzon* Jonathan D. Ketcham ${ }^{\dagger}$

*University of Pennsylvania, and NBER

${ }^{\dagger}$ University of California, Berkeley, and University of California, San Francisco

Copyright (C)2004 by the authors. All rights reserved. 


\title{
Reference Pricing of Pharmaceuticals for Medicare: Evidence from Germany, the Netherlands, and New Zealand
}

\author{
Patricia M. Danzon and Jonathan D. Ketcham
}

\begin{abstract}
This paper describes three prototypical systems of therapeutic reference pricing (RP) for pharmaceuticals-Germany, the Netherlands, and New Zealand-and examines their effects on the availability of new drugs, reimbursement levels, manufacturer prices, and out-of-pocket surcharges to patients. RPfor pharmaceuticals is not simply analogous to a defined contribution approach to subsidizing insurance coverage. Although a major purpose of RPis to stimulate competition, theory suggests that the achievement of this goal is unlikely, and this is confirmed by the empirical evidence. Other effects of RPdiffer across countries in predictable ways, reflecting each country's system design and other cost-control policies. New Zealand's RPsystem has reduced reimbursement and limited the availability of new drugs, particularly more expensive drugs. Compared to these three countries, if RP were applied in the United States, it would likely have a more negative effect on prices of on-patent products because of the more competitive U.S. generic market, and on research and development (R\&D) and the future supply of new drugs, because of the much larger U.S. share of global pharmaceutical sales.
\end{abstract}




\title{
Reference Pricing of Pharmaceuticals for Medicare: Evidence from Germany, the Netherlands, and New Zealand
}

\author{
Patricia M. Danzon, University of Pennsylvania, and NBER \\ Jonathan D. Ketcham, University of California, Berkeley, and \\ University of California, San Francisco
}

\section{Executive Summary}

This paper describes three prototypical systems of therapeutic reference pricing (RP) for pharmaceuticals-Germany, the Netherlands, and New Zealand-and examines their effects on the availability of new drugs, reimbursement levels, manufacturer prices, and out-of-pocket surcharges to patients. RP for pharmaceuticals is not simply analogous to a defined contribution approach to subsidizing insurance coverage. Although a major purpose of RP is to stimulate competition, theory suggests that the achievement of this goal is unlikely, and this is confirmed by the empirical evidence. Other effects of RP differ across countries in predictable ways, reflecting each country's system design and other cost-control policies. New Zealand's RP system has reduced reimbursement and limited the availability of new drugs, particularly more expensive drugs. Compared to these three countries, if RP were applied in the United States, it would likely have a more negative effect on prices of onpatent products because of the more competitive U.S. generic market, and on research and development (R\&D) and the future supply of new drugs, because of the much larger U.S. share of global pharmaceutical sales.

\section{Introduction}

Reference pricing (RP) is an approach to reimbursement for pharmaceuticals that is of considerable policy and research interest. Germany first formally adopted reference pricing in 1989, followed by the Netherlands in 1991 and New Zealand in 1993. British Columbia and Australia adopted reference pricing for specific therapeutic classes in 1995 and 1996, respectively. In the United States, reference pricing has been proposed as a possible approach to drug reimbursement for a comprehensive Medicare drug benefit (Huskamp et al. 2000). Reimbursement based on functional equivalence, which has been suggested for reimbursement of drugs that are already reimbursed under 
Medicare Part B, is essentially informal reference pricing. Japan has also debated adopting reference pricing to reform its system of pharmaceutical reimbursement.

Reference pricing is simple in concept: products are classified into clusters based on similar therapeutic effects. The payer sets a reference price (RP) for each cluster based on a relatively low-priced productfor example, the minimum or median price-in the cluster. The RP is the maximum reimbursement for all products in the group. Manufacturers may charge a price above the RP, but in that case the patient must pay the surcharge. If the manufacturer's price is less than the RP, the savings may be shared between the payer and the dispensing pharmacist, depending on system design.

The rationale for RP is to stimulate competition by informing consumers and physicians about substitutability between products. For example, de Vos (1996) explains the objectives of the Dutch reference pricing system:

[C]onsiderable effort was expended by the Dutch government to stimulate price competition in the pharmaceutical market .... Only when the necessary information about a specific medicine in relation to its substitutes is readily available can the demand side of the market, i.e., consumers, doctors, patients and insurance companies, make decisions on the fairness of prices. In the Netherlands, this objective was achieved by categorizing medicines into groups of interchangeable drugs and making doctors and patients aware of the interchangeability of medicines within such groups. (de Vos, 1996)

Because reference pricing controls the reimbursement but not the manufacturer's price, this approach is usually viewed as less restrictive than price controls and has been adopted in countries that previously had free pricing. Reference pricing is also in some ways similar to a defined contribution approach to insurance subsidization. The effects could be quite different, however, when applied to pharmaceuticals, as we discuss below.

In analyzing RP programs, it is critical to distinguish between generic referencing, which applies only to generically equivalent products with the same active ingredient and formulation, and therapeutic RP programs, which extend referencing to products with different active ingredients. Generic referencing is a well-established practice in the United States through maximum allowable charge (MAC) programs that are used by Medicaid and by some managed-care programs to reimburse for multisource compounds, that is, off-patent compounds with at least one generic product. The payer typically defines the MAC as the maximum reimbursement for all products with a given 
molecule, formulation, and strength, based on the price of a relatively cheap generic. A patient who wants the originator brand must pay any excess of the brand price over the MAC. Thus, U.S. MAC programs are reference pricing in all but name, and similar generic referencing systems have existed in the United Kingdom and some Canadian provinces for many years. Such generic referencing is relatively noncontroversial. It conserves third-party funds without exposing patients to significant risk because it applies substitution only between generically equivalent products that have demonstrated bioequivalence to the originator product. Moreover, because generic referencing applies only to off-patent products, it does not reduce effective patent life for originator products and hence has minimal effect on incentives for research and development (R\&D). Since the 1990s, generic referencing has been adopted by a growing number of countries, including Sweden, Italy, Spain, and Denmark.

Therapeutic referencing, as developed by Germany, the Netherlands, and New Zealand, extends the concept of substitutability from generically equivalent products (same molecule) to different molecules for the same indication. Therapeutic referencing is far more controversial because it treats compounds with different active ingredients as equivalent, despite possible differences in efficacy and/or side effects for at least some patients. Patients for whom the reference-priced product does not work face either higher copayments or health risks if they switch, which may be nonoptimal insurance coverage. Moreover, by clustering on-patent compounds with off-patent compounds, $\mathrm{RP}$ may reduce effective patent life and significantly affect incentives for R\&D.

A full analysis of reference pricing would address its effects on patients, on manufacturers, and on the efficiency of resource use. These issues are discussed below, but the empirical analysis is necessarily more limited, as is the existing literature. Previous studies have described the design of various countries' RP systems and reported data on drug spending either in aggregate or for a limited number of products in individual countries (see, for example, Danzon 2001, Lopez-Casasnovas and Puig-Junoy 2001, Jonsson 2001, and IoannidesDemos et al. 2002). Few studies of reference pricing use micro data. Studies of RP in Germany concluded that brand manufacturers generally dropped their prices to the reference price (Remit Consultants 1991, Maasen 1995, Danzon and Liu 1996). Similarly, Pavcnik (2002) found that manufacturers of hypoglycemics and H2-antagonists reduced their prices in response to the introduction of RP in Germany, 
and that branded products were affected more than generics. In other circumstances, however patients have faced significant surcharges and have switched away from surcharged drugs. Following the implementation of RP in British Columbia, patients reduced their utilization of higher-priced ACE inhibitors in favor of other antihypertensives with lower out-of-pocket costs (Schneeweiss et al. 2002). Thomas, Mann, and Williams (1998) report that in New Zealand, following a tender for the hydroxyl-methylglutaryl coenzyme A (HMGCoA) reductase inhibitor class, fluvastatin tendered the lowest price and established the subsidy $(\mathrm{RP})$ for the class. Patients receiving simvastatin faced a surcharge of NZ\$50.63 per month. Patients who switched to the fully subsidized fluvastatin experienced a significant increase in total cholesterol, LDL cholesterol, and triglyceride levels $(p<0.01)$.

Some of these results might suggest that RP succeeds in its objective of encouraging competition. The evidence from Germany is not representative of comprehensive RP systems, however, because new onpatent products were exempt from RP after 1996. Estimation of the effects of RP alone are confounded in all countries because other costcontrol measures were adopted. For example, in 1993, Germany introduced a global drug budget with physicians at risk for spending overruns, which strongly influenced physician prescribing (see Ulrich and Wille 1996), and in 1996, the Netherlands superimposed strict price controls on reference pricing. Because each country's RP system is different, generalization from single-country studies may be inappropriate. None of these previous studies has compared the effects of RP across countries with different system designs, and none has examined the effects of RP on the availability of drugs.

In this paper we first describe the main features of the RP systems in Germany, the Netherlands, and New Zealand and each country's other cost-control policies that may confound estimation of the effects of RP. Section III outlines a model of manufacturer response to reference pricing and develops hypotheses about the effects of RP on price competition and the availability of new drugs. Our empirical analysis combines data on reference prices from government sources and data on manufacturer prices from the market research firm IMS Health for five major therapeutic categories in 1998. ${ }^{1}$ Section IV describes the data. Section $\mathrm{V}$ reports the evidence on the availability of new products and the effects of competition and other factors on RPs, manufacturer prices, and patient surcharges. Section VI summarizes these findings from the three countries. Section VII compares RP to other possible 
models of insurance benefit design, in particular, a percentage coinsurance rate and tiered formularies. Section VIII discusses the implications of these findings for the proposed use of RP in the United States. The appendix summarizes differences among RP, price controls, and tiered formularies.

We find that RP has significantly reduced the availability of new compounds in New Zealand, which has the most aggressive RP system, and this effect is greatest for high-priced new products. There is no evidence that RP has encouraged competition, which is consistent with the hypothesis that prices tend to converge to and remain at the $\mathrm{RP}$ in the absence of other interventions. The findings that RP has tended to reduce reimbursement for recently launched products and that originator products are more likely to charge surcharges suggest that RP may reduce manufacturer incentives for innovation.

The experience of RP in these three countries has lessons for the United States and for other countries that may consider it. But we conclude that if RP were adopted in the United States, for example, for a Medicare drug benefit, it could have a much more negative effect on prices of on-patent drugs and on incentives for R\&D than occurred in these three countries. The structure of retail pharmacy in the United States results in a more price-competitive generic market, which in turn would put greater pressure on on-patent drug prices than occurs in other countries. Significant reductions in on-patent revenues in the United States could have a significant effect on incentives to develop new drugs given the dominant U.S. share of global pharmaceutical sales. Thus, whereas the United States is less likely than these smaller markets to experience nonlaunch of new drugs that are already advanced in the pipeline, the long-term effects on the supply of new drugs are likely to be more severe if RP is applied in the United States.

Reference pricing as analyzed here, which sets a single reimbursement price for different products that are considered interchangeable in a given country, should not be confused with cross national referencing, which is a form of price regulation used by many countries. Crossnational referencing sets the price of each product to the mean or median price of that same product in other countries. Such cross-national referencing is not expected to encourage price competition between therapeutic substitutes; rather, it constrains a manufacturer's ability to price-discriminate across countries for a given product, and the manufacturer's price cannot exceed the regulated price. 
Reference pricing is also distinct from tiered formularies used by pharmacy benefit managers (PBMs) in the United States. In a tiered formulary, products considered more cost-effective are placed on the preferred tier and carry a lower copayment than nonpreferred products on the higher tier. For example, the copayment structure may be $\$ 5, \$ 15$, and $\$ 30$ for a generic, preferred brand, and nonpreferred brand, respectively. The PBM negotiates discounts from drug manufacturers in return for preferred formulary status and the implied increase in market share. Thus, tiered formularies are used to promote price competition actively among therapeutic substitute drugs. However, PBMs usually apply RP only to generically equivalent, multisource compounds; that is, the preferred product in a molecule is a generic and patients who want the higher-priced originator brand must pay the excess of the brand price over the generic price. For therapeutic substitutes, although lower-priced products are more likely to be preferred, a product that is priced higher but is more effective may be on the preferred tier and reimbursed at a higher price than a less effective compound on either the same or the nonpreferred tier. Thus, compared to $\mathrm{RP}$, tiered formularies are designed to stimulate competition through negotiated discounts in return for preferred formulary status, and tiered formularies are more flexible in paying higher reimbursement for products that offer better efficacy, fewer side effects, or in other ways are more cost-effective. Implications of these differences between $\mathrm{RP}$ and tiered formularies are discussed in Section VIII.

\section{Reference Pricing in Germany, the Netherlands, and New Zealand}

Every RP system must define the rules for clustering drugs, including classifying new products, and for setting reference prices. This section describes the main features of each country's RP system through 1998, the year of our data. Post-1998 changes are also mentioned when they are relevant to understanding the evolution of these systems. We also describe each country's other pharmaceutical cost-control policies that potentially influence drug prices and volumes and hence must be considered in interpreting results. ${ }^{2}$

\section{Germany}

Germany adopted reference pricing in 1989. The federal government defined broad parameters but implementation was left largely to the 
Association of Sickness Funds (Bundesverband der Betriebskrankenkassen $[\mathrm{BKK}])$. The BKK defined the clustering system for drugs, subject to the approval of the physicians' association. The BKK also determined the reference prices. ${ }^{3}$

Classification. Unlike the Netherlands and New Zealand, Germany's RP system was phased in for different types of products and was not intended to be fully comprehensive. Class 1 includes products with the same active ingredient (generic referencing); class 2 applies to therapeutically and pharmacologically similar active ingredients; and class 3 applies to compounds with comparable therapeutic effect, especially combinations. Litigation over the definition of groups for classes 2 and 3 (particularly the clustering of newer, patented products with off-patent products) slowed implementation.

New Products. Following legislation in 1996, new on-patent products have been exempt from RP and are reimbursed in full without price controls. New generic products can join existing clusters with reimbursement at the prevailing RP.

As of January 2000, reference prices covered 197 active ingredients in class 1, 166 active ingredients in twenty-three groups in class 2, and thirty-one combinations in class 3 . These drugs accounted for roughly 50.3 percent of expenditures and 64 percent of scripts under Germany's statutory health system (VFA 2000).

Setting the Reference Price. Germany's method for setting RP levels was designed to reflect market prices more closely than in other countries. For each group, a standard formulation (for example, regular tablets of $20 \mathrm{mg}$ strength) was selected and an RP was set for that formulation within the range of manufacturer prices, with a higher RP set for product classes with few generic suppliers to encourage entry. The relative RPs for different formulations, strengths, and pack sizes were based on a quasi-hedonic regression (of Cobb-Douglas form) applied to manufacturer prices. RPs are revised annually, based on a review of actual manufacturer prices. In Germany, manufacturers have sometimes priced below the RP, which leads to reductions in RP levels in classes where the prevailing RP exceeded the average manufacturer price. As discussed below, this tendency for manufacturers to price below the RP in 
Germany probably reflects incentives created by the physician drug budgets rather than the RP system.

Physician, Pharmacy, and Patient Incentives. Physicians who prescribe a product priced above the RP are legally required to explain to the patient why the surcharged product is necessary. This stipulation creates an incentive for physicians to avoid products priced above the $\mathrm{RP}$, assuming that an explanation requires physician time that is not reimbursed. Information on product prices is made available to physicians.

Retail pharmacy in Germany is strictly regulated with respect to pricing, margins and entry. German pharmacists have traditionally lacked the authorization and the incentive to substitute low-priced generics or parallel imports (PIs) for higher-priced originator products. Until 2001, pharmacists were permitted to substitute a generic for a brand only if the physician prescribed generically, which occurred in only 5 percent of scripts (Schoffski 1996). ${ }^{4}$ German pharmacy dispensing margins are regulated and yield a higher absolute margin on higher-priced drugs, despite a declining percentage. To counteract these perverse incentives, Germany enacted legislation in 2001 that requires pharmacists to substitute a cheaper parallel import or generic if either is available.

Other Cost Controls: Physician Drug Budgets. The adoption of RP in 1989 did not stop the growth of drug spending. This outcome was hardly surprising because Germany's RP system applied initially to multisource products primarily. Of these, generics already accounted for 53 percent of scripts (Ulrich and Wille 1996). Moreover RP does not constrain volume or shifting to higher-priced products in other groups. ${ }^{5}$ Faced with the cost pressures of reunification with the former East Germany, in 1993 Germany increased patient copayments; imposed a 5 percent price cut on non-RP drugs; and adopted a national drug budget that set a limit on outpatient drug expenditures, initially at the 1991 spending level and subsequently updated by the GDP growth rate, with physicians collectively at risk for the first DM280m of any drug budget overrun (and the pharmaceutical industry at risk for the next DM280m). These measures led to a 19 percent decline in pharmaceutical expenditures; a decline in the number of prescriptions; and switching to cheaper products, including generics (Ulrich and Wille 1996). Some regions implemented physician-specific prescribing 
protocols and drug budgets, based on medical specialty and patient mix, but implementation was slow. The national drug budget was abolished in 2002.

Summarizing, under the German RP system without the drug budget, physicians, pharmacists, and patients did not have strong financial incentives to prefer drugs priced below the RP; hence, manufacturers had little incentive to set prices below the RP. ${ }^{6}$ To the extent that dynamic price competition with pricing below the RP occurred in Germany, this must be attributed to physicians being at risk for drug budget overruns, not to reference pricing.

\section{The Netherlands}

In the 1980s, relatively high prices and rapid pharmaceutical spending growth in the Netherlands made drugs a target for cost control, despite relatively low drug spending compared to other European countries. In 1991, a reference price system was introduced with the objective of improving information, cost-consciousness, and price competition (de Vos 1996).

Classification. Unlike Germany, the Dutch RP system was comprehensive from the outset; that is, it included almost all on-patent and offpatent drugs. Clusters were defined based initially on five criteria, which were reduced to four; then in 1999, they were reduced to the single criterion of clinically relevant differences in effects that are decisive for prescribing choices of doctors. ${ }^{7}$ Classification decisions are made by the Ministry of Health, with input from a panel of medical advisers. The clustering of new products has been frequently litigated, which has led to some revisions of the clusters over time. For example, the grouping of the new, more expensive migraine therapy sumatriptan in the same category with two older ergotamine products was challenged and settled only after a five-year lawsuit (Merck Frosst Canada 1996).

New Products. The Netherlands originally placed new, nonclusterable products on a separate list, list $1 b$, to be reimbursed in full. Following rapid growth of spending on list $1 \mathrm{~b}$ products (over 20 percent annually), list $1 \mathrm{~b}$ was closed in July 1993. New products could be reimbursed only if they joined an existing cluster, unless they were indicated for a disease for which no treatment existed. This stipulation led to a growing list of "waiting-room" products that were not admitted to outpatient reimbursement, even though they had marketing 
approval and might be available to hospital inpatients. Some manufacturers accepted listing with existing groups as the only way to get new products reimbursed; for example, the selective norepinephrine reuptake inhibitors (SNRIs) were grouped with selective serotonin reuptake inhibitors (SSRIs) and angiotensin-II antagonists with ACE inhibitors.

Since 1997, a new product that is not clusterable may be reimbursed if it is indicated for a disease for which no pharmacotherapeutic treatment is available; if another treatment exists, the new drug may be reimbursed only if it is cost-effective relative to the alternative and if sufficient budget funds are available.

Setting the Reference Price. The Netherlands' approach to the problem of defining a common price for different compounds is to define a standard daily dose for each compound, based on the World Health Organization (WHO) defined daily dose (DDD) system. The average price per DDD for each molecule is calculated as the unweighted average of the price per DDD of all originator and generic products in the molecule. The RP is then set at the median of the distribution, across molecules, of 1990 prices. These 1991 RPs remained in effect until 1999 apparently because this RP system created no incentive for manufacturers to reduce list prices below the RP and because list prices that were initially below the RP reportedly converged on the RP. The government therefore added direct price controls, as described below.

Pharmacy Reimbursement and Incentives. As in Germany, retail pharmacy in the Netherlands is regulated with respect to entry and pricing. Pharmacists are authorized to substitute a generic or a PI provided that the script is generically written and the patient is informed. ${ }^{8}$ Pharmacists receive a fixed dispensing fee per script, rather than a percentage of the product price, to encourage substitution toward cheaper products. To encourage dispensing of generics and PIs further, the pharmacist can retain one-third of the difference between the reimbursement price or RP and the list price of the cheaper substitute. However, pharmacists capture 100 percent of any manufacturer discounts below the list price, whereas they receive only one-third of any differential between the list price and the RP. Manufacturers therefore compete for market share by offering discounts off the list price rather than by reducing the list price. The magnitude of these discounts was estimated at NG300 to 400 million in 1994 (de Vos 1996). Thus, price 
competition occurred in the Netherlands but not because of the RP system. And it was not in a form that reduced list prices to generate savings for payers. In July 1998, the government introduced a partial "clawback" of the discounts through a 4.7 percent reduction in reimbursement rates to pharmacies.

Other Cost Controls: Maximum Price Regulation. After a 5 percent price cut in 1994, the Netherlands superimposed a new system (the Maximum of Price Law) of maximum price regulation in 1996 to reduce prices below levels generated by the RP system. The maximum price for each molecule/dosage form/strength was hereafter based on the average price in Belgium, France, Germany, and the United Kingdom, including generics and originator products. ${ }^{9}$ This change imposed a 15 percent price reduction on average and capped prices for many products below their RP. Thus, in the Netherlands, the Maximum Price Law made RPs nonbinding for many products and introduced dispersion of prices of different compounds within an RP cluster because of the variation in their maximum prices. In 1999, the RP levels were reduced based on these regulated maximum prices.

Thus, although reference pricing in the Netherlands was intended to promote price competition, in practice most list prices, including generics, reportedly clustered close to the RP until the Maximum Price Law invoked foreign price levels to force prices below the RPs. Competition did thrive but in the form of discounts off list prices rather than lower list prices, leading to profit for pharmacists, not savings for the government, at least initially. This competition was driven by the pharmacists' authorization and incentives to substitute generically equivalent products, including parallel imports, and was quite independent of therapeutic reference pricing.

\section{New Zealand}

New Zealand's outpatient pharmaceutical expenditures are managed by the Pharmaceutical Management Agency (Pharmac), a not-for-profit company owned by the Health Financing Authority. Pharmac's functions are similar to those of competing pharmacy benefit managers (PBMs) in the United States, except that Pharmac has monopsony power. Pharmac defines the Pharmaceutical Schedule, a formulary or positive list of roughly 3,000 prescription drugs and related products that are eligible for subsidy (reimbursement); negotiates prices with manufacturers and sets subsidy levels, if any; and designs and operates 
other cost-control strategies. The Schedule lists the price of each drug, the subsidy level, and the guidelines or conditions under which the drug may be prescribed. Consumers may purchase other approved drugs but without public subsidy. Pharmac is advised by a Pharmacology and Therapeutics Advisory Committee (PTAC) comprised of medical specialists and general practitioners whose role is to provide independent advice on the pharmacological and therapeutic consequences of proposed amendments to the Pharmaceutical Schedule, including review of company applications for Schedule listing and requests by Pharmac for removing items from the reimbursement list. Reference pricing was introduced in July 1993 with the intent to "reduce the excessive market segmentation based on brand marketing, which previously allowed suppliers to establish markets that were free from price competition" (Kletchko, Moore, and Jones 1995).

Classification. Almost all prescription drugs that are reimbursed in New Zealand are subject to reference pricing. Therapeutic subgroups are relatively broadly defined as "pharmaceuticals that produce the same or similar therapeutic effects in treating the same or similar conditions" (Kletchko, Moore, and Jones 1995). Patent status is not considered.

New Products. New products are generally reimbursed only if they join an existing subgroup, which requires offering a price below the prevailing RP (see below). A new product that is not clusterable into an existing subgroup may sometimes be reimbursed if Pharmac and the manufacturer can agree on a reimbursement price. For example, Serevent was listed after five years of negotiations; Imigran tablets were submitted for review four times in five years (Merck Frosst Canada 1996).

Setting the Reference Price. New Zealand sets the RP at the lowest price in each subgroup, regardless of patent status. In principle, manufacturers may charge a price above the RP. However, Pharmac may eliminate all subsidy for a product if a substitute product is available at a lower price and if Pharmac considers that the higher-priced product has no additional clinical benefit.

Unlike Germany and the Netherlands, Pharmac has used its monopsony power and the RP system to negotiate price cuts on new products, which then apply to all existing products in the RP cluster. Specifically, 
a new product is admitted to reimbursement in an existing RP cluster only if it is priced significantly below the prevailing RP. For generics, the first generic must offer a 30 percent price cut relative to the brand, the second must offer an additional 20 percent cut, and so on, although the required discounts for generics are becoming less rigid. These lower prices then define the new, lower RP for all products in that subgroup. Tendering is also used, with the lowest tendered price becoming the subsidy level for all drugs in the group.

Alternatively, the manufacturer of a new product may also offer a cross-therapeutic deal by reducing its price on another of its products in another therapeutic subgroup. A manufacturer may rationally prefer to give a large price cut on an old product with a small market share rather than accept a low launch price on a new product that it hopes will gain significant volume. Thus, Pharmac uses cross-therapeutic deals to negotiate larger price cuts than manufacturers might be willing to offer on new products. For example, in 1996, a 40 percent price cut on Tagamet was offered in return for a listing on the Schedule for Famvir, thereby reducing the RP of all $\mathrm{H} 2$ antagonists by 40 percent (Pharma Pricing Review 1996). The Schedule is updated monthly. Reference prices may thus change whenever a new product enters the market or following a therapeutic group review initiated by Pharmac.

Physician, Patient, and Pharmacist Incentives. Physicians and patients in New Zealand traditionally have had little incentive to be price-conscious. The patient copayment is the lesser of the cost of the drug or a fixed payment (which depends on welfare status) per script, plus any surcharge over the RP if the manufacturer's price exceeds the subsidy. Nonfinancial strategies to influence physician prescribing include provision of information, limiting certain drugs to specialists and/or specific conditions, and counterdetailing. Some physician associations also provide voluntary guidelines to their members, monthly charting of prescribing relative to the average, and similar services.

Retail pharmacy in New Zealand is heavily regulated. As in Germany and the Netherlands, restrictions on entry, prohibitions on nonpharmacist ownership and on branching, and other measures discourage retail price competition on drugs. Pharmacists were paid a fixed dispensing fee per script plus a percentage of the price. Although generic substitution rules permit the pharmacist to substitute generics unless the physician explicitly prescribes the brand and writes "no substitution," the traditional percentage margin reimbursement 
undermined incentives to substitute cheaper products that would yield a lower margin. In 1998, the government proposed replacing this fee based on percentage-of-price with a fixed dispensing fee.

Other Cost-Control Policies. In addition to RP for controlling prices, Pharmac uses other strategies to control drug volume and expenditures. National guidelines limit the prescribing of expensive medicines to certain conditions and/or to specialists. For example, Prozac was initially restricted and then made subject to an annual budget cap. In pay-to-play contracts, suppliers are paid a negotiated, up-front amount to make a product available at a lower price. Tendering, sole supply, and preferred supplier contracts are used to offer a supplier a larger market share in return for a lower price. In price-volume contracts, the price varies inversely with volume. Many generics are subject to such contracts. In average daily dose contracts, the subsidy is tied to a specified average daily dose and the supplier must pay a rebate if this average dose is exceeded, thereby shifting the risk of increasing daily dosage strength to the supplier. Listing of a new drug may also be contingent on the manufacturer accepting risk sharing through a capped annual budget with paybacks for overruns and possibly price reductions on drugs already listed.

In summary, although New Zealand's RP system by itself does not encourage competition, Pharmac has negotiated price cuts as a condition of admitting new products to reimbursement through the RP system, in addition to several other bargaining strategies.

\section{Modeling Effects of Reference Pricing}

A complete analysis of the effects of reference pricing would consider its effects on patients, including availability of drugs, out-ofpocket payments, and health outcomes; effects on drug expenditures and any increase in physician or hospital visits to deal with complications or prescription changes; and effects on manufacturers, including prices and volumes of new drugs and hence incentives for innovation. ${ }^{10}$

In this paper, we analyze the effects of RP on product launch decisions and hence the availability of new products and its effects on the reimbursement (RP level), manufacturer price, and implied patient surcharge, conditional on launch. Volume responses to surcharges and other factors are described in Danzon and Ketcham (2004, forthcoming). Our 
data set provides six months of data on RP levels and drug sales in our three countries in 1998. The great majority of products in our sample are under RP-96 percent in the Netherlands, 92 percent in New Zealand, and 62 percent in Germany, where on-patent products launched after 1996 and older products with few competitors were exempt from RP. The almost universal coverage of RP in the Netherlands and New Zealand, and the fact that we have only six months of sales data, preclude the use of formal difference-in-differences analysis to estimate the effects of RP. Our empirical analysis exploits the difference between drug cohorts by year of launch and exploits the differences among the three countries in their RP systems and other cost-control strategies. The following section outlines specific predictions.

\section{Effects of RP on the Launch of New Compounds}

Even in the absence of RP, other factors may lead to differences among the three countries in the launch of new compounds. If each country were a separate pharmaceutical market (so that manufacturers could pursue country-specific pricing policies), more products would be launched in markets with larger potential sales, assuming that any product launch entails certain fixed administrative and regulatory costs, independent of its potential sales. Thus, based on population size alone, Germany is expected to attract the most new compounds, followed by the Netherlands and then New Zealand.

In practice, although pharmaceutical price regulation remains a national prerogative, price spillovers across markets are potentially significant due to parallel trade and regulation based on foreign prices, so that a low price charged in one country can undercut prices in potentially higher-price markets. Parallel trade is authorized between member states of the European Union (EU). ${ }^{11}$ Regulation based on foreign prices occurs formally and informally in many countries. This potential for cross-national price spillovers is expected to make manufacturers less willing to launch new compounds in countries with low prices, especially countries with small potential sales volume (for evidence, see Danzon, Wang, and Wang 2002).

The reference price systems in our three countries are expected to exacerbate their relative attractiveness as markets for new compounds based solely on market size. Germany's RP system created negligible, if any, disincentive to the launch of new compounds because Germany defined clusters relatively narrowly and new patented products were exempt from RP after 1996. New Zealand's RP system is expected to 
have the most negative effect on the launch of new compounds, particularly potentially high-priced compounds, because New Zealand has the broadest criteria for defining product clusters and usually requires the manufacturer of a new product to offer a price below the established RP as a condition of being reimbursed in that cluster (or give a price cut in another cluster). Although the Netherlands, like New Zealand, required that most new products join an existing RP cluster as a condition of reimbursement, the Dutch criteria for product clusters were less broad than those in New Zealand, and RP levels were set relatively high (at the median of 1991 prices, which were reportedly high relative to European average prices, with no revision until 1999). After 1996, the Netherlands' prices were capped at the median of prices in the United Kingdom, Germany, France, and Belgium. Thus, it is an empirical question whether the resulting prices were sufficiently low to discourage the launch of new compounds. ${ }^{12}$ In 1998, the availability of new compounds in the Netherlands is expected to be similar to that observed in Germany, assuming that Dutch prices were constrained to levels similar to those in Germany and the United Kingdom, and that early delays in admitting new products to the Dutch RP system had been resolved.

\section{Effects of RP on Drug Prices}

If each country were a separate market, a drug manufacturer's pricing response to RP would depend on how RP and any other cost-control policies affect the price elasticity of demand, which in turn depends on the incentives of physicians; patients; and, if substitution is permitted, pharmacists. Under RP, patient demand is expected to be elastic at prices above the RP unless patients are informed about any differential product characteristics. Physician demand is also expected to be relatively elastic at prices above the RP, both as good agents for patients and because physicians may incur an unreimbursed time cost if they prescribe a drug that is priced above the RP. Physician drug budgets are expected to increase physician price sensitivity, including sensitivity to prices below the RP. Pharmacists are expected to be highly price sensitive if they can profit from the margin between the RP reimbursement and their actual acquisition cost of a generic substitute or parallel import. However, the effects of RP in a specific country may be mitigated by concern for cross-market spillover effects to prices in other countries. We discuss how these considerations apply in each of our three countries. 
In Germany, because RP applies only to therapeutic categories with multiple close substitute products, a monopolistic competition model is appropriate. ${ }^{13}$ Assuming monopolistic competition, the manufacturer's demand curve becomes kinked at the RP. At prices above the $\mathrm{RP}$, demand is relatively elastic because patients must pay for any surcharge and physicians face a time cost of explaining to patients if they prescribe a surcharged product. The kinked demand model predicts that manufacturers of originator and other relatively high-priced products would drop their prices to the RP unless this within-country elasticity effect is mitigated by potential revenue loss through cross-market spillovers-for example, if reducing the price in Germany would result in lower prices in other countries, say, Italy or the Netherlands, which both cross-reference Germany in setting their own prices. ${ }^{14}$

Germany's RP system alone created no incentives for physicians, patients, or pharmacists to be price-sensitive at prices below the RP; hence, the RP system created no incentives for dynamic competition to reduce prices over time. Because Germany's physicians were financially at risk for drug budget overruns, however, their general price sensitivity due to drug budgets could in theory create incentives for manufacturers to charge prices below the RP. Such competitive pressure on prices is expected to be greater in classes with multiple generic substitutes (same compound and hence, almost perfect substitutes) than from therapeutic substitutes (different compounds and hence, imperfect substitutes). Thus, in Germany, prices are predicted to be inversely related to the number of competitors, particularly generic competitors, in a class. Because Germany revised the RP levels periodically based on actual manufacturer prices, RP levels are also predicted to be inversely related to the number of competitor products in a class. But note that, aside from the initial incentive for high-priced products to drop their price to the RP, these dynamic competitive effects in Germany result from the physician drug budgets, not from the structure of the RP system.

In the Netherlands, predicting the effects of the RP system is complicated by the maximum price ceilings. Under the RP system alone, the kinked demand model predicts that in classes with multiple competing products, prices would converge to the RP, except that surcharges may survive for originator products if concerns about external price spillovers dominate market share concerns in the Netherlands. Manufacturers had no incentive to cut list prices below the RP because neither physicians nor patients had incentives to be price-sensitive 
below the RP and pharmacists were more price-sensitive to discounts off the list price than to reductions in list prices. Moreover discounts would not trigger price spillovers to other countries. (Note that discounts off list prices are unobservable in our data, which include only list prices.) For product classes with few competitors, oligopoly may be a more appropriate assumption; although many models are possible, aggressive price competition is unlikely. Thus, under assumptions of either monopolistic competition or oligopoly, RP alone would not induce competition.

The Netherlands' experience with RP was dominated, however, by the 1996 Maximum Price Law, which imposed binding, moleculespecific price ceilings that were frequently below the RP for each compound. There was no incentive for manufacturers to set list prices below these price ceilings. Thus, in the Netherlands, neither prices nor RPs are expected to be influenced by competition induced by the RP system. The 1998 RPs reflect the price distribution that prevailed in 1991, when the RP system was enacted. The 1998 prices reflect the regulated price caps based on foreign prices, which may imply some price dispersion depending on prices in the benchmark countries. Consequently, prices in the Netherlands are expected to vary inversely with the number of competitors to the extent that such conditions prevailed in the benchmark foreign countries (United Kingdom, Germany, Belgium, and France). In fact, market and regulatory systems in all these countries would plausibly lead to an inverse relation between prices and the number of competitor products (see Danzon and Chao 2000); in which case, prices in the Netherlands should vary inversely with the number of competitor products. However, this would reflect foreign experience and assumes correlation across countries in the number of competitors by therapeutic class.

In New Zealand, the kinked demand model predicts that manufacturer prices would converge down to the RP, in the absence of manufacturer concerns about cross-market spillovers and assuming elastic demand at prices above the RP. Although neither physicians, patients pharmacists have incentives to be price-sensitive at prices below the $\mathrm{RP}, \mathrm{RP}$ levels and prices are nevertheless predicted to be inversely related to the number of competitors in a class because Pharmac uses its monopsony power to negotiate a reduction in the RP as a condition of permitting a new product to join an existing class. 
In summary, the structural differences among the three countries' RP systems, together with differences in other controls, lead to the specific predictions discussed in the subsections below.

Availability of New Compounds. The probability of the launch of new compounds is expected to be greatest in Germany and least in New Zealand, particularly for new compounds launched after 1993 and for relatively high-priced products.

Price Compression. Reference pricing is expected to compress the range of reimbursement levels (subsidies) and manufacturer prices within each therapeutic class, with greater compression in countries with broad criteria for defining classes and where the RP is based on the minimum manufacturer price in the class. Greatest downward compression of RP levels is therefore expected in New Zealand, which has the broadest criteria for defining clusters and sets the RP at the lowest manufacturer price in each cluster. Germany's RP system is expected to impose the least compression on both RPs and manufacturer prices; however, Germany's physician drug budgets create additional incentives for manufacturers to constrain relatively high prices and even price below the RP, which confounds the predictions based on RP alone. The Dutch RP system alone created incentives for convergence of list prices to the RP, but the 1996 Maximum Price Law capped many prices below their RPs and led to the dispersion of prices below the RP. Thus, for the Netherlands, price dispersion within classes is possible due to price regulation, not to competition induced by the RP system. ${ }^{15}$

Originators Versus Generics. Reference pricing is expected to reduce RP (subsidy) levels and manufacturers' prices of originator products relative to subsidies and prices of parallel imports and generic substitutes because RP levels are generally based on relatively low-priced products in each class without regard to patent status. Prices of originators may still be higher, but the difference is expected to be smaller under RP than under free pricing. Unfortunately, none of our countries provides a benchmark for completely unregulated pricing. For some analysis, we use Germany as a benchmark of relatively free pricing of new products because it exempted new patented products from its RP system after 1996. 
Price Competition. Although RP was intended to stimulate competition, this effect is limited to an incentive for high-priced products (usually originators) in crowded categories to drop prices to the RP. There is no incentive for manufacturers to price below the RP and indeed, if RPs were set above the lowest price, these prices may converge upward. Thus, RP alone creates no incentive for dynamic price competition in the absence of other controls or structural features that make physicians, patients, or pharmacists sensitive to prices below the RP. In Germany, however, drug budgets created incentives for manufacturers to compete on price, and in New Zealand, Pharmac used its monopsony power to bargain for a price reduction as a condition of admitting new products to reimbursement in an established class. Thus, in both Germany and New Zealand, prices and RPs are predicted to vary inversely with the number of competitors. For the Netherlands, any apparent influence of the number of competitors on RPs reflects competitive pressures as of 1991, before the introduction of the RP system; for prices, any influence of the number of competitors reflects competition or regulation in the benchmark countries from which the price caps were imported.

Surcharges. The kinked demand model predicts that demand would be highly elastic at prices above the RP and that manufacturers would drop prices to the RP (zero surcharge) if products in a class are good substitutes or if patients are unaware of any differences in efficacy or side effects possibly because physicians do not take the time to explain. Thus, surcharges are expected only for products with relatively inelastic demand because of actual or perceived superior characteristics, or if cross-national spillovers risks are significant. Both effects are more likely for originator products than for generics.

\section{Data}

The data for this study include, for each country, all products with sales reported by IMS in the first half of 1998, for five major therapeutic categories: anti-ulcerants (A02); hypoglycemics (A10); antihyperlipidemics (C10); antidepressants (N06); and antihypertensives, which are further subdivided by mode of action into cardiac therapy (C01), diuretics (C03), beta blockers (C07), calcium channel blockers (C08), and ACE inhibitors and angiotensin-II antagonists (C09). ${ }^{16} \mathrm{We}$ 
obtained sales data from IMS and RP (subsidy) data from the agency responsible for reimbursement in each country.

We use the IMS data to calculate price per dose (IMS standard unit) at manufacturer prices in U.S. dollars. ${ }^{17}$ The data from these two sources were matched at the pack level to permit comparisons of prices to subsidy levels. A surcharge per standard unit for each pack was defined as the price minus the subsidy per standard unit. Extreme values of this surcharge were used to remove outlier packs. Molecule-level prices, RPs, and surcharges are defined as volume-weighted averages of the corresponding pack-level variables for each country.

We define two measures of age for each molecule. Country-specific age is measured in months from the first launch date of any product in the molecule in a given country to the latest date of the observation period (June 1998). Global molecule age is the maximum of the three country-specific age variables. These age measures apply to all products in a given molecule. Other measures of product value and market competition are defined below. Measures of molecule age and the number of generic and therapeutic competitors were calculated before the removal of outlier packs.

\section{Empirical Results}

\section{Availability of New Compounds}

Of the 200 molecules in our sample, Germany has 175, of which 109 (62 percent) are reference-priced; the Netherlands has 118, of which 108 (92 percent) are reference-priced; and New Zealand has 95, of which 91 (96 percent) are reference-priced. The much larger number of molecules available in Germany is consistent with expectations given Germany's larger market size and its relatively narrow criteria for defining RP clusters, flexibility in setting RP levels, and exemption from RP of on-patent products launched after 1996. Similarly, New Zealand's relatively small number of launches is consistent with predictions given its small population and its comprehensive RP system, with relatively broad clusters and requirements for price cuts from new entrants.

Table 1.1 lists the availability of molecules categorized by their global molecule age (first launch date in our three countries) to test whether New Zealand and, to a lesser extent, the Netherlands experienced reduced availability after 1991, compared to Germany, because of their more restrictive RP systems. This rough difference-in-differences analysis uses Germany as the control group because Germany's RP 
Table 1.1

Availability of molecules, as of 1998 by molecule global launch date

\begin{tabular}{lllll}
\hline Global launch & Total & Germany & The Netherlands & New Zealand \\
\hline Prior to 1987 & 126 & 114 & 69 & 67 \\
& & $90 \%$ & $55 \%$ & $53 \%$ \\
1987-1990 & 27 & 24 & 21 & 15 \\
& & $89 \%$ & $78 \%$ & $56 \%$ \\
1991-1994 & 22 & 20 & 13 & 10 \\
& & $91 \%$ & $59 \%$ & $45 \%$ \\
After 1994 & 25 & 17 & 15 & 3 \\
& & $68 \%$ & $60 \%$ & $12 \%$ \\
\hline
\end{tabular}

was least restrictive and new on-patent compounds were exempt after 1996. More recent drug cohorts are expected to be less widely available in all three countries because of lags in diffusion.

For Germany, the percentage of molecules available does not show a strong trend after the introduction of reference pricing in 1989 compared to the pre-RP period, with roughly 90 percent of compounds launched. After 1994, this declines to 68 percent of the post-1994 cohort launched, which may reflect diffusion lags with censored data. The Netherlands has fewer molecules launched after the introduction of reference pricing in 1991 (59 to 60 percent) compared to 78 percent in 1987 to 1990 immediately prior to RP. This finding suggests that the Netherlands' requirement that most new products join established RP clusters as a condition of reimbursement deterred the launch of some new compounds. This conclusion is tentative because the Netherlands also has relatively few (55 percent) of the pre- 1987 cohort. RP may have led to early withdrawal of some older molecules in the Netherlands because of relatively low reimbursement (see figure 1.1), so our data would underestimate the total number of older (pre-1987) molecules launched. Withdrawing cheap old products that might reduce the $\mathrm{RP}$ for new products could be a rational strategy for manufacturers, particularly in classes with few competitors.

For New Zealand, there is a dramatic decline in availability for more recent molecule cohorts. Whereas New Zealand has 53 percent of molecules launched before 1987, it has 45 percent of molecules launched from 1991 to 1994 and only 12 percent of molecules launched from 1995 to 1998. This very low availability of the 1990s cohort of new molecules in New Zealand cannot simply be attributed to its generally longer launch lags. ${ }^{18}$ The sharply reduced availability of new compounds 


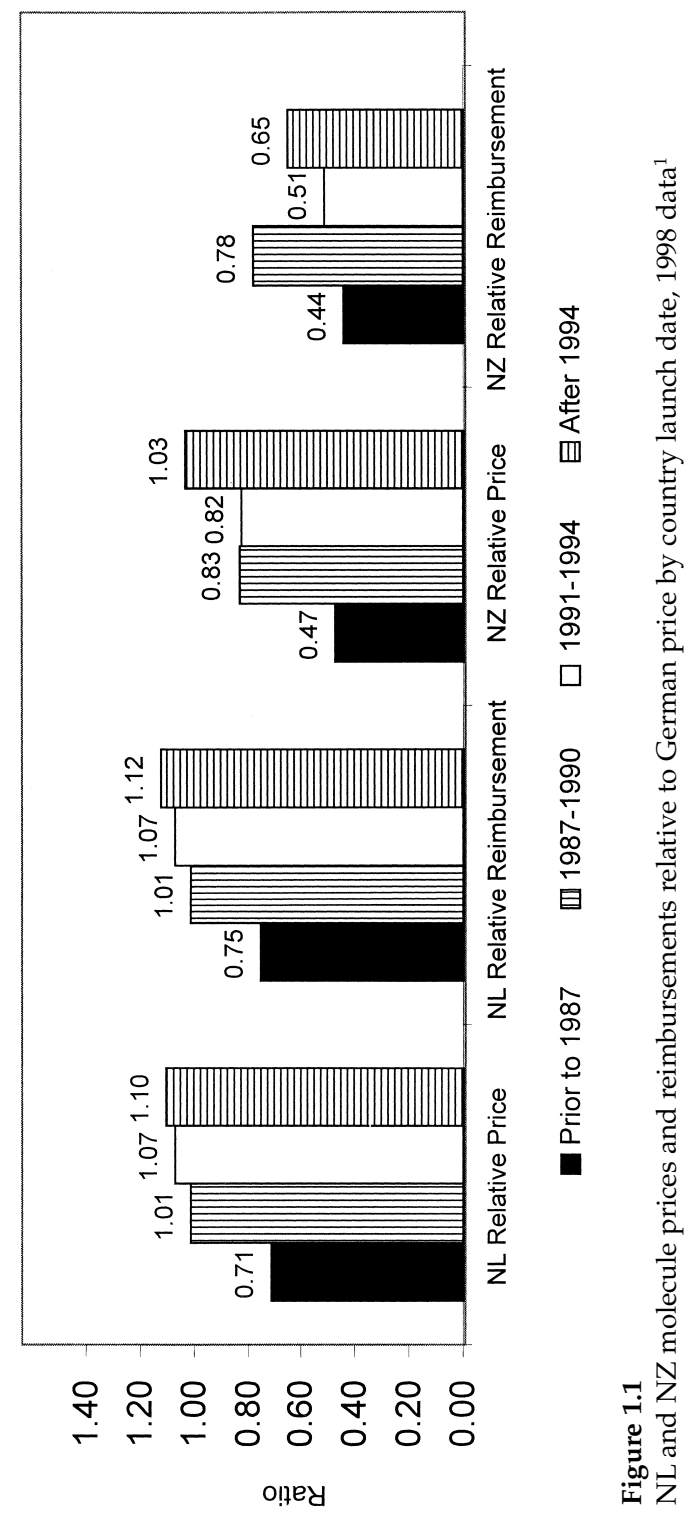


in New Zealand after 1994 is consistent with predictions, given its requirement that new drugs accept reference pricing and give a price cut relative to the prevailing $\mathrm{RP}$, which was already the lowest price of established products in the class.

As an additional measure of availability of new molecules, table 1.2 lists the availability and mean launch lag of the forty-three new medical entities (NMEs) launched in the United States between 1991 and 1998, where launch lag is measured relative to a compound's first launch in any of these three countries or the United States. ${ }^{19}$ Because Germany exempted new patented products from RP after 1996, we divide the sample into molecules launched before and after that date. For all three countries, the availability of these NMEs is less for NMEs launched post-1996 compared to the 1991-1995 period, which may partly reflect lags in diffusion combined with right-censored data. For New Zealand, however, there is a dramatic drop, from 50 percent of the pre-1996 molecules to 13 percent of the post-1996 molecules launched. The declines are less dramatic in Germany (from 93 percent to 73 percent) and the Netherlands (from 82 percent to 62 percent). The mean and median launch lags for introduction of these NMEs are lowest for Germany and highest for New Zealand. Thus, even for the limited subset of molecules that are introduced, launch lags are longer in the Netherlands and longest in New Zealand compared to Germany.

To test whether this reduced availability of drugs in New Zealand and, to a lesser extent, the Netherlands might be related to low RPs in these countries, figure 1.1 shows the median ratios of RPs and prices in the Netherlands and New Zealand, respectively, relative to Germany.

Table 1.2

Availability and launch lag (months) of new medical entities (NME) launched in the United States 1991-1998, as of 1998

\begin{tabular}{cllll}
\hline & Total & Germany & The Netherlands & New Zealand \\
\hline $\begin{array}{c}\text { Availability } \\
\text { NME 1991-1995 }\end{array}$ & 28 & 26 & 23 & \\
& & $93 \%$ & $82 \%$ & 14 \\
NME 1996-1998 & 15 & 11 & 10 & $50 \%$ \\
& & $73 \%$ & $67 \%$ & 2 \\
Lag of available & Mean & 5.8 & 6.8 & $13 \%$ \\
molecules $^{\text {a }}$ & Median & 0 & 1 & 19 \\
& $n$ & 37 & 33 & 12 \\
\hline
\end{tabular}

a Lag defined as the number of months after earliest of FDA date, launch in Germany, NL, or NZ. 
Molecules are categorized by Country-specific launch date rather than Global launch date to reflect country-specific regulatory regimes. The sample of molecules is restricted to those available in both Germany and the comparison country. ${ }^{20}$ Median rather than mean values are reported because means are very sensitive to outlier values. For the Netherlands relative to Germany, the median RP ratio increases from .75 for compounds launched before 1987 to 1.12 for compounds launched after 1994; the Netherlands/Germany price ratios follow a similar upward trend. Thus, for compounds launched under reference pricing, Dutch RPs and manufacturer prices are typically 7 to 12 percent higher than German prices as of 1998. For the post-1994 molecule cohort, the Dutch price ratios are lower than the RP ratios, which may reflect the constraints imposed by the Dutch Maximum Price Law, which capped prices for most molecules below their respective RPs and hence made the RPs nonbinding. In general, the finding of lower prices and RPs in Germany than the Netherlands for molecules launched after 1990 may reflect the stronger incentives for dynamic price competition in Germany due to the physician drug budgets. By increasing physicians' price sensitivity, these budgets created incentives for manufacturers to price below the initial RP levels, which permitted consequent downward revisions of RPs in Germany.

For New Zealand, by contrast, median RP ratios are over 40 percent lower than those in Germany, for three of the four time periods, whereas median prices range from 53 percent lower to 3 percent higher than those in Germany, with the lowest prices and RPs for the oldest cohort. Thus, in general, RPs and manufacturer prices are much lower in New Zealand than in Germany or the Netherlands, as expected given Pharmac's use of bargaining to negotiate cuts in prices and RPs as a condition for the entry of new products. The surprising exception is that post-1994 molecules are priced 3 percent higher on average in New Zealand than in Germany, although RPs are 35 percent lower. A plausible explanation is biased selection; that is, these newest molecules were launched in New Zealand only if they could charge a price comparable to European levels. This interpretation is consistent with the small number of post-1994 molecules launched in New Zealand compared to earlier cohorts, as shown in table 1.2. ${ }^{21}$

To test whether aggressive RP systems are biased disproportionately against relatively expensive drugs, figure 1.2 reports price and RP ratios for the Netherlands and New Zealand relative to Germany, with the sample of molecules divided based on the price distribution in 


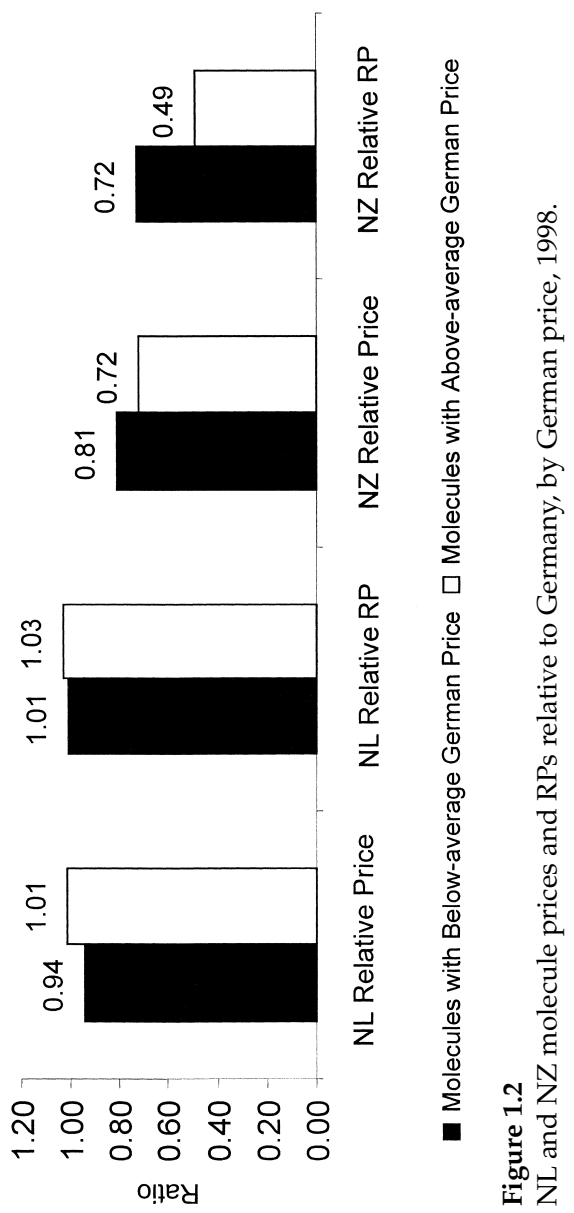


Germany. We use Germany as the benchmark because it has the most molecules and because its price distribution is expected to reflect potential free market prices more closely. For the Netherlands, the median RPs are 1 to 3 percent higher than the German RPs for products in the lower and upper halves of the price distribution. For prices, the Netherlands' median price relatives are lower for molecules that are low-priced in Germany than for higher-priced molecules (0.94 versus 1.01). This finding suggests that the Dutch Maximum Price regulations were more binding for lower-priced molecules, possibly because generics are included in calculating the price ceiling. The Netherlands also has a higher percentage of the higher-price molecules: 71 percent of the high-price molecules compared to 57 percent of less-expensive molecules. This situation may reflect the greater incentives to launch higher-priced products due to relatively high reimbursement and/or early withdrawal of products with relatively low reimbursement.

In New Zealand, by contrast, RP levels are disproportionately lower for more expensive drugs than they are for less expensive drugs, and with greater compression of RPs for high-price rather than low-price drugs $(0.49$ versus 0.72$)$ than for prices $(0.72$ versus 0.81$)$. This suggests that manufacturers charge higher surcharges on more expensive products to partly make up for lower RPs. However, the bias against expensive products is also reflected in availability, with only 44 percent of the more expensive drugs available in New Zealand compared to 51 percent of the less expensive drugs.

In summary, Dutch RPs and prices were typically at or above German price and RP levels (except for the oldest cohort, which has prices and RPs below those in Germany). The smaller differential for prices reflects the Netherlands' regulated price ceilings based on foreign referencing that imposed stricter controls than did the ineffectual RP system (until the RPs were cut in 1999). Thus, the Dutch RP system failed to reduce manufacturer prices until additional, externally regulated controls were added in 1996. The relatively low price levels in Germany, together with other evidence of dynamic downward revisions of prices and RPs in Germany over time, were largely due to the global drug budget that placed physicians at risk for overruns, whereas the RP system created no incentives for manufacturers to set prices below the initial RP levels.

In New Zealand, Pharmac's requirement that new products offer a price below the prevailing RP as a condition of admission to reimbursement, thereby reducing the RP for existing products, succeeded in 
reducing RP levels to 51 percent of German levels for drugs launched from 1991 to 1994. It appears to be less effective for the post-1994 cohort of new drugs, but this may reflect selection bias: only 13 percent of the post-1996 cohort of new drugs was launched in New Zealand during our observation period, and presumably those that were launched did so because they were able to obtain a relatively high price. Moreover, in New Zealand relative prices are always higher than the relative RPs compared to Germany, and these differentials are greater for expensive products. Overall, these results confirm that New Zealand's RP system has set relatively low reimbursement levels, particularly for the newest drugs and the most expensive drugs. Many of these drugs are simply not available in New Zealand and for those that are available, patients on average face out-of-pocket surcharges.

\section{Compression of Reimbursement Within Drug Classes}

An important issue in defining RP systems is the degree of consensus about the substitutability of different drugs. A finding of consistency across countries in classification and relative RP levels for different drugs suggests broad clinical agreement about the relative merits of different molecules, even though the formal criteria differ across countries and absolute RP levels may differ. On the other hand, if the classification systems and relative RPs differ significantly across countries, this suggests either significant clinical disagreement in defining clusters or that budgetary concerns in practice override clinical judgment. Given the broader criteria for defining classes in New Zealand, we predict greater compression of RPs across drugs within a therapeutic category in New Zealand.

Although our data do not permit us to compare classification systems, we can compare the compression of reimbursement across molecules within each broad therapeutic category. The compression of RPs provides a bottom-line measure of the effect of the classification structure because a separate subgroup for improved products in a therapeutic category is relevant only to the extent that the RP for this subgroup differs from the RP for inferior products. Table 1.3 reports several measures of the compression of RPs across molecules within each therapeutic category (the sample is restricted to molecules that are available in all three countries).

The results are generally consistent with expectations. In most country-class cells, there is a considerable range in RPs. New Zealand has the lowest median and maximum RPs for eight of the nine therapeutic 
Reference Pricing of Pharmaceuticals for Medicare

Table 1.3

Measures of reimbursement dispersion within ATC2s based on molecule average, 1998 data $^{\mathrm{a}}$

\begin{tabular}{|c|c|c|c|c|c|c|c|c|}
\hline ATC2 & $N$ & $\begin{array}{l}\text { Mini- } \\
\text { mum }\end{array}$ & Median & $\begin{array}{l}\text { Maxi- } \\
\text { mum }\end{array}$ & $\begin{array}{l}\text { Max/ } \\
\min \end{array}$ & $\begin{array}{l}\operatorname{Max}- \\
\min \end{array}$ & $\begin{array}{l}(\mathrm{Max}- \\
\min ) / \\
\text { median }\end{array}$ & $\begin{array}{l}\text { Standard } \\
\text { deviation }\end{array}$ \\
\hline \multicolumn{9}{|c|}{ Germany } \\
\hline $\mathrm{A} 2$ & 22 & 0.04 & 0.21 & 1.62 & 39.66 & 1.58 & 7.61 & 0.45 \\
\hline A10 & 13 & 0.03 & 0.10 & 0.56 & 16.56 & 0.53 & 5.42 & 0.14 \\
\hline $\mathrm{C} 1$ & 5 & 0.07 & 0.23 & 0.70 & 9.63 & 0.63 & 2.79 & 0.24 \\
\hline $\mathrm{C} 3$ & 26 & 0.04 & 0.12 & 0.61 & 16.83 & 0.58 & 4.79 & 0.12 \\
\hline $\mathrm{C} 7$ & 21 & 0.07 & 0.26 & 0.52 & 7.39 & 0.45 & 1.75 & 0.14 \\
\hline $\mathrm{C} 8$ & 14 & 0.11 & 0.33 & 0.73 & 6.49 & 0.61 & 1.88 & 0.18 \\
\hline C9 & 17 & 0.20 & 0.36 & 0.76 & 3.75 & 0.55 & 1.56 & 0.16 \\
\hline $\mathrm{C} 10$ & 20 & 0.07 & 0.39 & 0.89 & 12.76 & 0.82 & 2.09 & 0.23 \\
\hline N6 & 34 & 0.04 & 0.28 & 1.37 & 32.64 & 1.32 & 4.70 & 0.40 \\
\hline \multicolumn{2}{|c|}{ Median: } & 0.07 & 0.26 & 0.73 & 12.76 & 0.61 & 2.79 & 0.18 \\
\hline \multicolumn{9}{|c|}{ The Netherlands } \\
\hline $\mathrm{A} 2$ & 14 & 0.07 & 0.70 & 1.72 & 24.92 & 1.65 & 2.34 & 0.56 \\
\hline A10 & 7 & 0.05 & 0.11 & 0.48 & 9.97 & 0.43 & 3.78 & 0.15 \\
\hline $\mathrm{C} 1$ & 3 & 0.07 & 0.09 & 0.32 & 4.73 & 0.25 & 2.93 & 0.14 \\
\hline $\mathrm{C} 3$ & 11 & 0.06 & 0.09 & 0.21 & 3.73 & 0.15 & 1.65 & 0.06 \\
\hline $\mathrm{C} 7$ & 17 & 0.07 & 0.22 & 0.59 & 8.53 & 0.52 & 2.39 & 0.13 \\
\hline $\mathrm{C} 8$ & 12 & 0.14 & 0.39 & 0.98 & 6.82 & 0.83 & 2.12 & 0.24 \\
\hline $\mathrm{C} 9$ & 14 & 0.24 & 0.55 & 0.88 & 3.72 & 0.64 & 1.17 & 0.18 \\
\hline $\mathrm{C} 10$ & 11 & 0.05 & 0.44 & 1.34 & 28.00 & 1.29 & 2.92 & 0.43 \\
\hline N6 & 22 & 0.04 & 0.21 & 1.32 & 35.53 & 1.28 & 6.08 & 0.43 \\
\hline \multicolumn{2}{|c|}{ Median: } & 0.07 & 0.22 & 0.88 & 8.53 & 0.64 & 2.39 & 0.18 \\
\hline \multicolumn{9}{|c|}{ New Zealand } \\
\hline $\mathrm{A} 2$ & 13 & 0.00 & 0.16 & 0.83 & 547.60 & 0.82 & 5.01 & 0.27 \\
\hline A10 & 5 & 0.04 & 0.08 & 0.09 & 2.32 & 0.05 & 0.64 & 0.02 \\
\hline $\mathrm{C} 1$ & 3 & 0.02 & 0.03 & 0.14 & 6.69 & 0.12 & 4.18 & 0.07 \\
\hline $\mathrm{C} 3$ & 10 & 0.01 & 0.03 & 0.12 & 12.28 & 0.11 & 3.43 & 0.04 \\
\hline $\mathrm{C} 7$ & 12 & 0.01 & 0.05 & 0.28 & 26.52 & 0.27 & 5.56 & 0.09 \\
\hline $\mathrm{C} 8$ & 7 & 0.18 & 0.36 & 0.71 & 3.87 & 0.53 & 1.48 & 0.19 \\
\hline $\mathrm{C} 9$ & 9 & 0.10 & 0.17 & 0.71 & 7.17 & 0.61 & 3.63 & 0.19 \\
\hline $\mathrm{C} 10$ & 11 & 0.00 & 0.31 & 0.93 & 9306.17 & 0.93 & 3.04 & 0.27 \\
\hline N6 & 20 & 0.03 & 0.19 & 1.04 & 34.12 & 1.01 & 5.24 & 0.29 \\
\hline \multicolumn{2}{|c|}{ Median: } & 0.02 & 0.16 & 0.71 & 12.28 & 0.53 & 3.63 & 0.19 \\
\hline
\end{tabular}

aSample restricted to molecules with data available in all three countries.

Note: Shading indicates the lowest value for each cell across the three countries. 
categories, and the lowest range and standard deviation for seven and six categories, respectively. The normalized range, defined as (maximum - minimum)/median, is lowest in New Zealand for only two of the nine categories, presumably because the low median offsets the high range. This is additional evidence that New Zealand's approach (using broad criteria for defining clusters and setting the RP at the lowest price in each class) has resulted in greater compression of RPs across molecules in a therapeutic category than has the less restrictive criteria used in the Netherlands and Germany. We estimated similar distributions using the product and the pack as the unit of analysis. Results were very similar to the molecule-level distributions reported in table $1.3 .^{22}$

\section{RPs, Prices, and Generic Competition}

$\mathrm{RP}$ is often rationalized as a mechanism to stimulate competition (see, for example, Kletchko, Moore, and Jones 1995) because the payer pays the same price for all products in a cluster. The monopolistic competition model implies that firms that previously priced above the RP would likely reduce their prices to the RP, while firms that previously priced below the RP may increase their prices, leading to a convergence of prices on the RP. Dynamic downward pressure on prices is not expected except where other programs create incentives or constraints for pricing below the RP, such as Germany's physician drug budgets or New Zealand's requirement for price cuts from new entrants. Thus, the prediction is that, under $\mathrm{RP}$, prices would be inversely related to the number of competitors in Germany and New Zealand but not in the Netherlands unless this effect was "imported" from pre-RP prices (which were the basis of the initial RP levels) or from foreign prices through the maximum price ceilings. Because our database is a halfyear cross-section of prices, we cannot measure price changes in response to RP. Nevertheless, these 1998 data do reflect several years of experience under RP for all three countries.

Our multivariate analysis estimates reduced-form, quasi-hedonic equations for RP, price, and surcharge per unit for all products in our sample in each country. Standard hedonic price equations estimate the relationship between prices and product characteristics or cost factors that influence demand or marginal cost. Our regressions are quasihedonic because the perfect competition assumption of standard hedonic theory does not apply to pharmaceutical markets, which are imperfectly competitive and subject to regulation. Our equations 
therefore include measures of competition and indicators of regulatory regime in addition to product characteristics.

The quasi-hedonic estimating equation for the price of product $i$ in molecule $j$ in therapeutic class $k$ can be written as follows:

$P_{i j k}=\alpha_{0}+\alpha_{1} Z_{j k}+\alpha_{2} N^{g}{ }_{j}+\alpha_{3} N^{t}{ }_{k}+\alpha_{4} R_{i j}$

where $Z_{j k}$ is a vector of product quality dimensions and other characteristics that are expected to influence demand, $\alpha_{2}$ reflects the effect of the number of generic competitors $N^{g}{ }_{j}$ in molecule $j$, and $\alpha_{3}$ reflects the effect of the number of therapeutic substitutes (other compounds) in class $k$ $\left(N_{k}^{t}\right)$. We predict $\alpha_{2}, \alpha_{3}<0$, and $\left|\alpha_{2}\right|>\left|\alpha_{3}\right|$ if generic competition exerts greater downward pressure on prices than does therapeutic competition. $R_{i j}$ is a vector of indicators for regulatory regime.

Because RPs are based on lagged manufacturer supply prices, RPs are expected to reflect the same product and market characteristics that affect prices. Surcharges are defined as the difference between the price and the $R P$; hence, the surcharge equations test for significant differences in coefficients between the RP and price equations. ${ }^{23}$ We use the same specification but estimate separate equations for each country. This approach permits all coefficients to vary across countries and facilitates comparison of coefficients across countries. One exception is that the Parallel Import indicator is omitted from the New Zealand equations because there are no parallel imports in New Zealand.

Product Characteristics. Pharmaceutical prices are expected to depend on the value of the product to consumers and the extent of competition. We include several measures of product efficacy. A quadratic in Global molecule age (log), defined as months from the molecule's first launch in any of our sample countries, is included as a general proxy for product efficacy. Newer compounds are expected to have higher prices, assuming that they are clinically superior on average to older molecules. A dummy variable controls for herbal products and molecules that were launched before 1950, for which the IMS age data are imprecise. Strength, defined as grams of active ingredient per unit, is included as a proxy for product potency. The coefficient is expected to be positive, assuming that a stronger dose of a given compound has greater expected efficacy. Indicator variables are included for Retard, Liquid, and Transdermal formulations; regular tablets and capsules is the omitted category. Retard forms are expected to have higher prices, assuming that delayed release forms offer greater 
convenience to patients. Pack size (units per pack) is expected to be negatively related to price if economies of scale in packaging are passed on to consumers.

An Originator product indicator is included to test for brand loyalty. The coefficient is expected to be positive in the price equation but not in the subsidy equation if brand loyalty persists among physicians and/or patients, but RP systems do not reflect these differences. An indicator variable is included for parallel imports (PIs); the coefficient is expected to be negative in the price and subsidy equations if the savings from PIs is captured by payers. Measurement of this effect may be confounded, however, by nonrandom entry of PIs, that is, if products that attract PIs are disproportionately high-priced products. For example, omeprazole (Prilosec), which is priced well above average in Germany, has nine parallel import products, whereas most compounds have none; in the Netherlands, omeprazole has five parallel imports.

Indicator variables for three-digit Anatomical therapeutic classes (ATCs) are included to control for unmeasured differences in average product value by therapeutic category. The ACE inhibitors and angiotensin-II antagonists (C09) are omitted as the reference group.

Competition. We include three measures of competition: Generic Competitors measures the number of manufacturers in the molecule; Molecules in the three-digit ATC is a measure of therapeutic substitute compounds; and Products of other molecules in the four-digit ATC is a measure of the intensity of competition within the therapeutic substitute molecules. In Germany, RPs and prices are expected to be negatively related to the number of generic and therapeutic competitors because RP levels were initially set lower in classes with more competitors and because Germany's drug budgets made physicians pricesensitive, thus creating incentives for price competition that enabled subsequent downward revisions of RPs.

In the Netherlands, RPs are expected to be inversely related to the number of competitors only to the extent that the 1991 price structure on which they were based reflected competition. For prices, the Dutch RP system did not encourage competition in list prices; hence, prices are expected to be related to the number of competitors only to the extent that this was imported through the maximum price caps. In New Zealand, RPs are expected to be inversely related to the number of generic and therapeutic competitors because of Pharmac's requirement that new entrants to a class give a price cut relative to the existing 
RP. The estimated relationship may be biased by reverse causation, however, if manufacturers were more likely to introduce products to classes with higher RPs. In all three countries, the kinked demand model predicts greater price competition at prices above the RP than below the RP. Because we lack the data to identify these ranges separately, the estimates in table 1.4 reflect the average effects over the full range of prices.

Regulatory variables. Our tests for differential regulatory effects focus on the year of launch of the molecule in each country because launch prices establish the base from which prices adjust over time, with price increases rarely permitted in regulated markets. We use molecule rather than product launch date because generic and other later entrants in an established molecule are constrained by the price and reimbursement of the originator product in the molecule under both RP and competitive regimes. We include variables indicating molecules launched in the country from 1987 to 1990, from 1991 to 1994, and after 1994. The last two categories roughly identify compounds launched under RP; their coefficients are expected to be negative if RP systems are biased against new products. The omitted category is products launched before 1987 and hence before RP. These older compounds are likely to be off-patent by 1998, but the effect of generic entry should be captured by our measure of generic competitors. $^{24}$

In all regressions we include an indicator for products that are not reference-priced (Not-RP). Because these products are not randomly chosen but are mostly new products or products that could not be clustered, this variable does not identify the effects of reference pricing. For Germany, where products outside the RP system were usually fully reimbursed, the coefficient of the Not-RP indicator is expected to be positive in the subsidy equation if RP lowers reimbursement levels on average. The surcharge for these observations is zero by definition. For New Zealand, non-RP molecules typically are not reimbursed, so the coefficient of the Not-RP indicator is expected to be negative in the subsidy equation, positive in the surcharge equation. For the Netherlands, some non-RP products are reimbursed; others are not. ${ }^{25}$

Empirical Results. Table 1.4 reports estimates of the price, subsidy, and surcharge regressions, with the pack as the unit of observation. Estimates using the product as the unit of analysis are very similar 


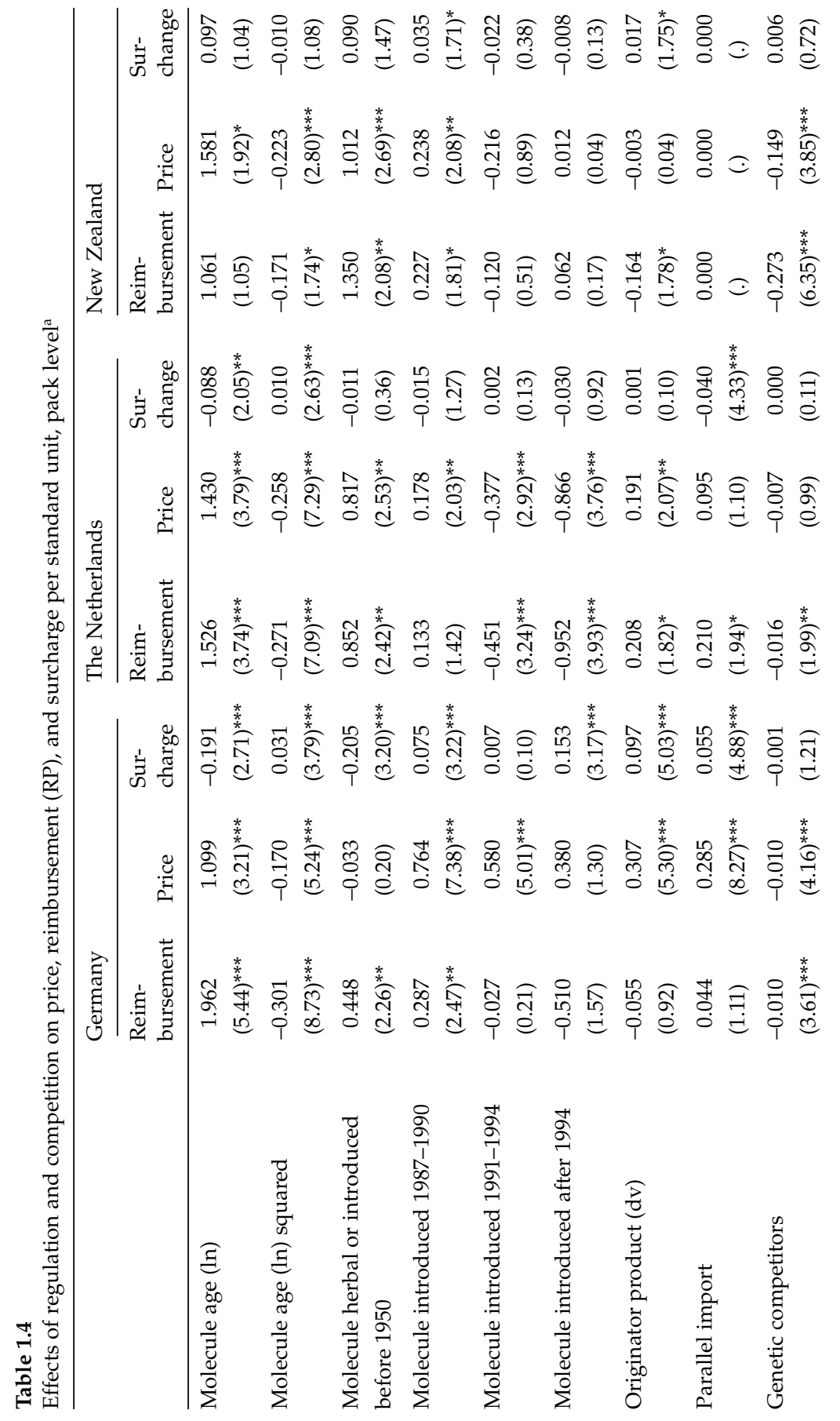




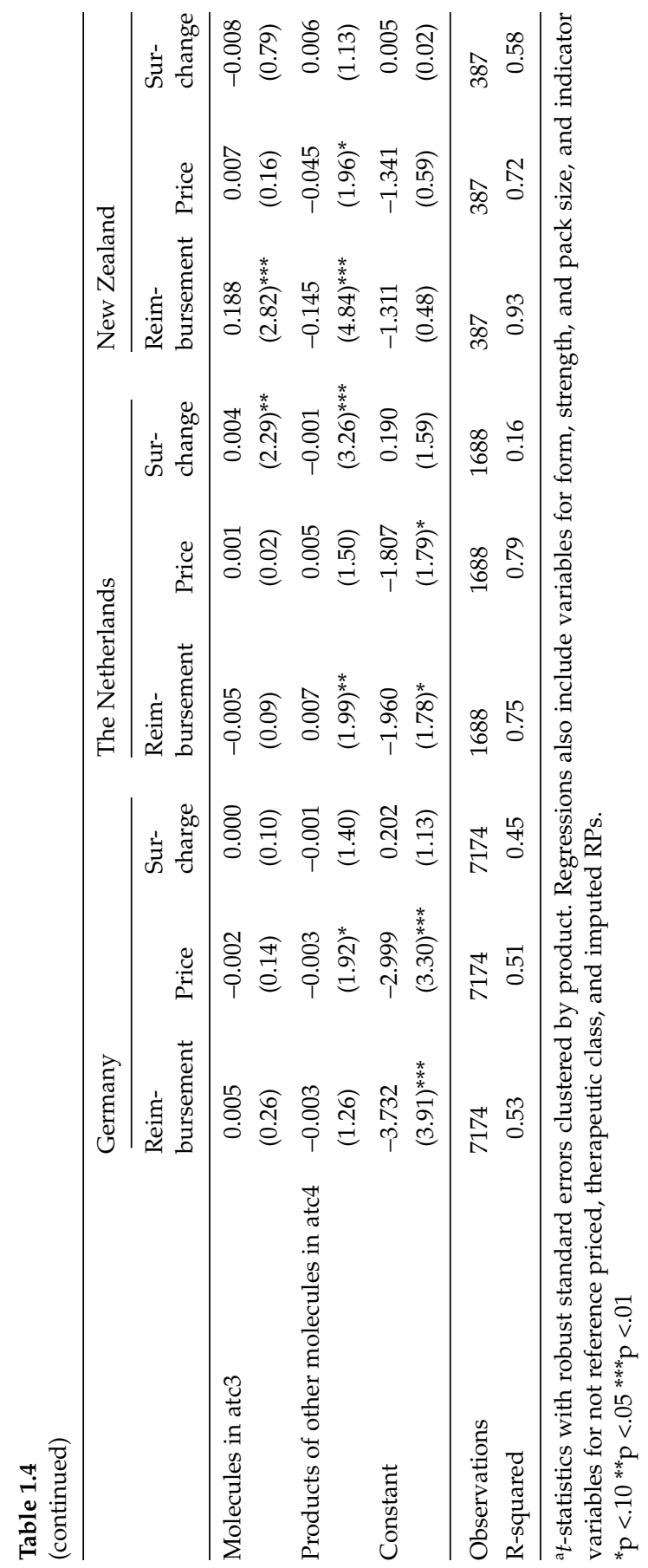


and are not reported here. Table 1.4 reports $t$ statistics based on robust standard errors and adjusted for clustering across packs within a product.

The quadratic in Global Molecule Age (a proxy for product efficacy) implies that price and subsidy initially increase and then decrease with molecule age. These effects are significant for price, subsidy, and surcharge in Germany and the Netherlands, but only for price in New Zealand. The estimates imply that price and subsidy are highest for molecules launched within the most recent two years and then decline for older molecules, as expected under the hypothesis that older products are generally perceived to be less effective and thus are sold at lower prices and receive lower subsidies. (Note that these estimates control for the number of competitors, which increases with molecule age and is a control for patent status.) In Germany and the Netherlands, surcharges are also significantly higher for newer products, reaching a maximum for two-year-old products in Germany and seven-year-old products in the Netherlands. This implies that RP offers lower subsidy differentials for new products than the price differentials that are supported by the market.

The regulatory variables imply that, after controlling for Global Molecule Age and Number of Competitors, in all three countries RP subsidies for new compounds were similar to the subsidies for compounds launched prior to 1987 (which were presumably mostly off-patent by 1998). By contrast, subsidies for compounds launched from 1987 to 1990, that is, compounds that were probably still on-patent in 1998 but launched prior to RP, received higher subsidies. In the Netherlands, molecules launched after 1991, i.e., under the RP system, received lower subsidies than did molecules launched before 1987, with most negative effects for the most recent, post-1994 compounds. The pattern is similar in Germany, although significance levels are lower. Specifically, in Germany, the post-1991 compounds have subsidies comparable to pre1987 compounds, whereas the compounds launched from 1987 to 1990, which would primarily be compounds that were launched before the RP system but that are still on-patent in 1998, receive the highest subsidies. Similarly, in New Zealand, the more recent compounds launched under RP have subsidies similar to the pre-1987 compounds, whereas compounds that were launched from 1987 to 1990, before the adoption of reference pricing, have higher subsidies, prices, and surcharges.

In Germany the newest, post-1994 molecules have the highest surcharges, whereas surcharges are not related to regulatory regime in the 
Netherlands, presumably because of the price controls. In New Zealand, prices, surcharges, and subsidies are highest for compounds launched prior to RP.

Originator products do not receive higher subsidies than do generics in Germany, consistent with the intent of generic referencing, and in New Zealand originator products receive 16 percent lower subsidies. In the Netherlands, originators receive roughly 21 percent higher subsidies than generics. Because these coefficient estimates reflect both betweenmolecule and within-molecule differences, even the Netherlands' estimate of a small positive differential is not necessarily inconsistent with the expectation that RP eliminates subsidy differentials for originator versions of a given pack, compared to generic versions of that same pack, as predicted under generic referencing. By contrast, originator price differentials over generics are significant in Germany (31 percent originator price differential) and the Netherlands (19 percent originator differential). Out-of-pocket surcharges are significantly higher on originator products in Germany and also New Zealand, where they are small in magnitude on average. In the Netherlands, the originator surcharge differential is insignificant, possibly because of the maximum price constraints.

In Germany, parallel imports do not receive significantly different subsidies but they do charge higher prices and have positive surcharges. In fact, the similarity between the PI coefficient (.285) and the originator coefficient (.307) suggests that, in Germany, PIs simply shadow-price the originator products, yielding little savings to payers or patients, which is additional evidence of weak incentives for price competition under Germany's RP system. Not surprisingly, the PI market share was small in Germany. In the Netherlands, the PI coefficient is similar to the originator coefficient for subsidies but smaller for price; thus, the PI surcharge is negative but small in magnitude. Taken at face value, these results indicate little savings to payers from PIs. These conclusions are tentative because the PI coefficients may be upward biased if PIs are more likely to enter for high-priced products.

The evidence on competition is generally consistent with the kinked demand model, as adapted to fit each country's RP system. The number of Generic Competitors is negatively related to both subsidies and prices in both Germany and New Zealand. In Germany, the estimates imply that each additional competitor leads to only a 1 percent reduction in subsidy or price. This small marginal effect of additional generics is consistent with weak incentives for generic competition under RP 
in Germany. It is also not surprising because most generics in Germany are branded; hence, they compete on brand image and reputation, which contrasts with unbranded generics that predominate in the United States and compete predominantly on price. In New Zealand, the marginal effect of an additional generic competitor is 27 percent for subsidy and 15 percent for price. These effects presumably reflect the requirement that new generic entrants offer a reduction in price and $\mathrm{RP}$ as a condition of reimbursement. In the Netherlands, the number of generic competitors has a significant but small (1.6 percent) effect on subsidy but no significant effect on price, which is expected given the lack of incentives to compete on list price. The number of products in substitute molecules has an economically small negative effect on subsidies in Germany and on surcharges in the Netherlands, but a larger and more significant negative effect in New Zealand, with a more negative effect for subsidy than for price, again possibly because of the regulatory requirement that new entrants accept lower prices and hence reduce the RPs for the entire class. Thus, the evidence on the effects of generic competition under RP is consistent for intramolecular and closely related generic competitors: by itself, RP does not encourage generic competitors to compete on price. Downward price pressure occurs only when this is enforced through regulation, as in New Zealand, or where other institutional factors outside the RP system create incentives for price competition, such as drug budgets in Germany or off-list discounting to pharmacists in the Netherlands.

Similarly, there is no evidence of price competition from therapeutic substitutes in any of the three countries. On the contrary, in New Zealand subsidy levels are significantly positively related to the number of molecules in the ATC3. These estimates may reflect endogeneity bias if new compounds enter the New Zealand market only if they can obtain a relatively high subsidy level, as shown in table 1.3.

Other product characteristics included in the estimating equations but not reported here generally have the expected signs. Subsidy and price are generally positively related to strength (grams of active ingredient) per dose and negatively related to pack size. Retard forms have significantly higher subsidies and prices than regular tablets (the omitted category), with similar magnitudes in all three countries. This finding suggests that manufacturers apply standard markups for these more costly forms. For transdermal forms, Germany has significantly higher subsidies, whereas New Zealand's subsidies do not differentiate between transdermal and standard oral forms. Products that are not 
reference-priced are generally not reimbursed in New Zealand, which is reflected in a large negative coefficient on the Not-RP indicator in the subsidy equation. By contrast, in the price equation, the Not-RP indicator is positive, indicating that these are relatively high-priced products.

The subsidy coefficients for several of the therapeutic category indicators are statistically significant, relative to the omitted category (ACE inhibitors), but coefficient magnitudes and even signs differ across countries. This tends to confirm the earlier evidence of a lack of consistent evaluation across countries of the relative merits of different products and/or that budget imperatives override clinical judgments.

\section{Conclusions on Effects of RP on Availability, Subsidies, and Prices}

This evidence on the impact of reference pricing is broadly consistent with predictions given the differences in system design across our three countries. We find that New Zealand's RP system (which is most comprehensive, has the broadest classes, and uses monopsony power to obtain price reductions) is associated with significantly reduced availability of new products, particularly for more expensive compounds. Availability is also somewhat reduced in the Netherlands.

In all three countries, subsidies for molecules launched in the postRP period are comparable to subsidies for (mostly off-patent) compounds launched before 1987 and are lower than subsidies for (mostly on-patent) compounds launched in the 1987-1990 period immediately prior to RP. These estimates control for cohort therapeutic effects and the number of competitors. Compared to older compounds, surcharges for the more recent drugs are positive in Germany, implying some willingness of consumers to pay more for newer products than was reflected in subsidy levels. Surcharges are negative in the Netherlands, but because both prices and RPs were set by regulation, this provides no evidence of market willingness to pay. In New Zealand, surcharges do not appear to be differentially higher on new products, but these conclusions are tentative because of small numbers.

Although a major objective of RP systems is to stimulate competition, there is no evidence of competition among therapeutic substitutes in any of the three countries. Although both subsidies and prices are inversely related to the number of generic competitors, magnitudes are 
small in both the Netherlands and Germany and may reflect other factors: physician drug budgets in Germany and, in the Netherlands, influences imported from the pre-RP era or from other countries through external referencing. In New Zealand, subsidies and, to a lesser extent, price are significantly negatively related to the number of generic competitors, but this finding reflects the regulatory requirement of price cuts from new entrants. This failure of generic referencing to stimulate competition in these three countries reflects the details of their system design: in particular, the regulation of pharmacy margins and weak incentives for pharmacists to substitute cheaper products. The exception is the Netherlands, where competition did occur but is not observable in these data on list prices because it took the form of discounts off list price, which yielded savings to pharmacies, not to payers, until the discounts were clawed back. An important conclusion is that the effects of RP in any country will depend critically on the structure of pharmacy incentives to substitute cheaper products. We discuss this further below when we consider the effects of adopting $\mathrm{RP}$ in the United States.

The evidence from regression analysis, that therapeutic referencing has not stimulated dynamic competition, is consistent with the kinked demand model of manufacturer response to RP. This conclusion is also supported by other circumstantial evidence, that all three countries found it necessary to adopt additional measures to control prices. In particular, the Netherlands adopted maximum prices based on foreign prices because their internal RP system had not stimulated dynamic competition as intended, and the resulting regulated prices made the RPs irrelevant for many products. In 2001, Germany mandated that pharmacies increase substitution of PIs and cheaper generics where available. Thus, Germany's RP system alone did not stimulate significant generic competition, which is not surprising because it gave no incentive to pharmacists to substitute cheaper products. New Zealand has used additional measures-requiring a price cut from new entrants and tendering-to enforce dynamic price competition. This has achieved lower prices, particularly on relatively expensive new compounds, but at the cost of reduced availability of these new compounds. In conclusion, both theory and empirical evidence support the conclusion that reference pricing, as structured in these three countries, did not deliver its main intended benefit of stimulating competition between substitute products except when it was implemented with aggressive monopsony power, as in New Zealand. 


\section{Reference Pricing as Efficient Insurance Benefit Design}

Standard models of optimal insurance coverage focus on the trade-off between risk spreading and cost control in the context of moral hazard; medical services are usually implicitly assumed to be competitively supplied at prices equal to marginal cost. While the risk-spreading versus cost-control trade-off is also relevant to pharmaceutical benefit design, the optimal insurance structure for drugs must also consider the effects of reimbursement on drug prices and hence on manufacturers' incentives for innovation and provider/patient incentives for substitution between products. A formal model of optimal drug coverage is beyond the scope of this paper. In this section, we draw on existing models to suggest conclusions about the efficiency and equity of RP compared to alternatives such as a proportional co-insurance rate or a formulary with tiered copayments.

Standard models of optimal insurance conclude that, in an ideal world where the insurer has perfect information about the patient's condition and the appropriate treatment, the insurance payment would be an indemnity payment equal to the cost of treatment, and moral hazard would not exist. More realistically, when the insurer cannot observe the patient's condition and therefore treatment is determined by the physician/patient team subject to moral hazard, optimal insurance coverage (assuming reliance on demand management) involves a trade-off between risk spreading and lower premium payments (Pauly 1968, Zeckhauser 1970, Ma and Riordan 2002). Specifically, the optimal patient cost share for different conditions is greater, when the demand for treatment is more price elastic (Ma and Riordan 2002).

Applying this result to the RP context of patient heterogeneity in their response to different drugs, the optimal patient copayment schedule is likely to require some cost sharing between the patient and the insurer for the incremental cost of more expensive drugs, with the patient paying a larger share of the incremental cost as demand becomes more price elastic. RP pays an indemnity equal to the cheapest drug in a class, with 100 percent patient cost sharing for the incremental cost of more expensive drugs. Generic referencing is consistent with optimal insurance coverage for generically equivalent compounds because these products are required by regulation to be bioequivalent. Thus, differential patient response is generally not an issue. For therapeutic substitutes that differ in their effects for different 
patients, however, RP is unlikely to provide the optimal trade-off between risk spreading and cost control for patients who do not respond to the cheaper drug. $\mathrm{RP}$ is likely to be inferior to a co-insurance rate, which would provide some risk protection for the incremental cost of more expensive drugs for these patients. RP is also likely to be inferior to a tiered formulary, which would typically include several drugs on the preferred tier, even if they are priced differently, if patients are heterogeneous in their response to the different compounds in a class.

Similarly, from the perspective of equity, if patients differ in their response to drugs due to genetics, comorbidities, or other factors, and if the objective is to use public funds to ensure that everyone has a uniform basic level of care, then equity requires higher subsidies to higher-priced drugs if these are needed by some patients to achieve the target care level. If all drugs in a class are reimbursed at the price of the cheapest or most widely tolerated drug in the class, patients with comorbidities and those taking several other drugs-who may also be the sickest patients-may be most likely to face surcharges to obtain a drug that they can tolerate. By analogy, defined contribution insurance plans would pay risk-adjusted subsidies to sicker patients to enable them to buy the same basic care that healthy patients can buy with lower subsidies. By fully subsidizing only the cheapest product in a class, RP systems fail to risk-adjust the subsidy rate and thus do not enable patients for whom the cheapest drug is ineffective to achieve the same outcomes as other patients for whom the cheapest drug is effective.

Optimal insurance coverage for drugs should also take into account the effects of the subsidy structure on prices to suppliers and hence on incentives for innovation. Assume that the term and structure of patents are optimally set and that the price differential between onpatent and generic drugs is optimal before insurance. If insurance with therapeutic RP is introduced with a classification system that ignores patents, it effectively gives a full subsidy to generics but a zero subsidy to the patent-induced price differentials of on-patent drugs. This raises the relative out-of-pocket price of on-patent drugs faced by patients. This may lead manufacturers of on-patent drugs to reduce their prices if demand is highly elastic above the RP. But in any case, revenues of on-patent products will decline relative to revenues for generics, and incentives for innovation are reduced, particularly for drugs that offer improved treatments within existing categories, which are most likely to be subject to RP. By contrast, insurance with a fixed co-insurance 
rate or a tiered formulary would imply some insurance coverage of the on-patent price differential.

In practice, the optimal insurance share of the price differential between on-patent drugs and old generics depends on the incremental value of the innovation and on whether the patent structure is in fact optimal. Whether current patent protection is excessive, suboptimal, or just right cannot be determined a priori. But if the current rate of innovation is considered about right, then therapeutic RP, which reduces effective patent life for all but the first entrant in a new class, would reduce incentives for $R \& D$ to develop improved therapies within existing classes and result in suboptimal innovation compared to the status quo mix of proportional co-insurance and tiered copayment structures. ${ }^{26}$ This conclusion still holds if both the generic and the on-patent drug are subject to a fixed copayment. This interaction between insurance coverage and incentives for innovation is another reason why the defined contribution approach to subsidizing insurance breaks down when applied to drugs. Insurance plans do not incur large fixed costs of $R \& D$ and rarely generate patentable innovations. Thus, patents are not relevant to the design of optimal subsidies for insurance coverage. By contrast, given the large fixed costs of R\&D (both absolutely and as a percentage of total costs) and the importance of patents for innovator drugs, the optimal subsidy structure for pharmaceuticals cannot ignore the effects on incentives for innovation.

If RPs have a significant influence over manufacturer prices, as the theory and evidence above suggest, then RPs can influence price signals and hence efficiency of resource use. In particular, because the RP for different products is not necessarily differentiated based on their relative effectiveness, RP can distort prescribing choices. Appropriate incentives for resource use and for innovation require that compounds that are less effective or that require a longer course of treatment to achieve a given outcome should be reimbursed less per daily dose than more effective drugs or drugs that require fewer days or doses to achieve the same outcome. In practice, cost-effectiveness criteria are not used rigorously to set RPs. Typically, the RP applies to the daily dose of each drug in a class, regardless of differences in effects or required duration of treatment. By contrast, both a proportional coinsurance and a tiered copayment structure can easily tailor differences in reimbursement to reflect differences in efficacy. For example, a higher-priced but more effective drug could be on the preferred tier of a PBM formulary and receive a higher reimbursement than a 
cheaper but less cost-effective, inferior drug. We don't suggest that PBMs consider only cost-effectiveness and not budget costs in designing their formularies. The point is simply that the tiered formulary structure can easily reimburse different drugs in proportion to their differing effectiveness, and this sends appropriate signals for prescribing choices and for R\&D. By contrast, RP systems tend to set equal reimbursement rates per daily dose for different drugs, regardless of differences in efficacy, which sends distorted signals for prescribing and for R\&D.

\section{Implications for the United States}

Reference pricing has been proposed for a Medicare drug benefit in the United States under the assumption that this benefit would be delivered by a single monopoly PBM in each geographic area (Huskamp et al. 2000, and more generally, Kanavos and Reinhardt 2003). If RP is simply an option that can be used by competing PBMs, then the use of monopsony power would be more limited and competitive forces would contrain its use to classes where drugs are highly interchangeable for most people. In fact, the limited evidence from private-sector PBM experience with RP suggests that the classes for which there was sufficient clinical consensus to adopt RP accounted for only roughly 30 percent of total ingredient cost. Despite a roughly 25 percent shifting from nonpreferred to preferred agents, estimated savings to the plan were only 1 percent of total drug spending (Sanders 2001).

$\mathrm{RP}$ would potentially play a larger role if PBMs are constrained from using tiered or otherwise restrictive formularies, which is likely if each area is served by only one PBM to avoid problems of risk selection. Huskamp et al. (2000) propose that PBMs periodically compete for the franchise in a particular area, but the successful bidder in each area would serve the entire area. In that case, seniors would have no choice of PBM, so the single monopoly PBM would probably be required to offer all drugs on an open formulary with a standard co-insurance or copayment rate, rather than on a tiered formulary typically offered by PBMs in the private sector. Such restrictions would eliminate the ability of PBMs to negotiate discounts from manufacturers in return for preferred formulary status, which would deprive them of their major tool for controlling drug prices. As an alternative, Huskamp et al. (2000) propose reference pricing. RP could also result as the drug product analogy of an "any willing provider" requirement that has been 
proposed for the participation of pharmacies in a Medicare drug benefit.

Although none of these proposals provide a detailed outline of how RP might work for Medicare, to achieve significant savings, it would have to include on-patent products, presumably with off-patent products, and exclude only first-in-class new products, as in the Netherlands and New Zealand. It would also presumably be a single national system. What does experience from these countries and from the U.S. system of RP for off-patent medicines tell us about how such a system might work in practice?

First, it is critical to distinguish between drugs in classes with only on-patent originator drugs versus classes that include generic versions of off-patent drugs. Presumably most new classes would start off as onpatent-only but would become mixed (on- and off-patent drugs) over time. For the on-patent-only classes, if the RP is set at the lowest price in the class, other prices would likely drop to the RP, except that some surcharges might remain for clearly differentiated products. There would be little incentive for dynamic price competition below the initial RP, however, unless the government agent used its monopsony power to demand price cuts from new entrants, as in New Zealand. ${ }^{27}$

Competitive bidding would probably not be an effective strategy unless winning bidders get some preferential placement on the formulary, which is precluded by the assumption of an open, nontiered formulary. With an open, nontiered formulary, each firm has little incentive to bid a low price ex ante because this would just increase the probability that the RP is low without increasing that firm's expected market share (because other competitors could reduce the prices to the $\mathrm{RP}$ once it had been set). Thus, an open formulary requirement eliminates a payer's ability to negotiate discounts. One possible outcome is that the Medicare RP system might take competitive bids and, following the lead of many state Medicaid programs, adopt prior authorization requirements for drugs that do not match the lowest bid price. This is a restrictive formulary in all but name. If firms still failed to bid low under this approach, the Medicare RP system might simply require that all firms give a specified discount off their private-sector prices or face prior authorization requirements, which is the approach adopted by many state Medicaid programs. This approach would achieve lower prices but through the exercise of monopsony power, not through competitive forces operating under the RP system as envisaged by proponents of the RP approach. Thus, unless an RP system exploits its 
monopsony power, it would be less effective at achieving competitive controls on prices than would PBMs that use tiered formularies because the tiered formularies enable the PBM to negotiate competitive discounts in return for moderate increases in market share. This conclusion that RP without either monopsony power or some formulary restrictions would be ineffective at controlling prices of on-patent drugs is limited, however, to classes with on-patent products only.

For mixed classes that include both on-patent molecules and offpatent molecules with generic products, the effect of RP on prices of the on-patent products could be dramatic, assuming that pharmacy incentives remain the same as under current maximum allowable charge (MAC) programs. Here, the experience of other countries with RP systems is misleading because their structure has been far less successful at stimulating generic competition than has the U.S. approach to generic referencing. Three factors contribute to greater generic competition under U.S. MAC programs than under RP in the countries studied. First, the default rule in the United States is that pharmacists can substitute a generic for a brand unless the physician expressly writes "brand required." Second, U.S. pharmacists have incentives to substitute the cheapest generic available because they capture the difference between the MAC reimbursement and the drug acquisition cost, whereas pharmacists in countries with regulated margins typically earn less if they dispense a lower-priced product. U.S. pharmacists' ability to profit from dispensing cheaper generics makes their demand highly price-elastic, which in turn gives generic manufacturers an incentive to compete on price. Third, payers in the United States capture much of the savings from generic competition by periodically reducing the MAC based on audits of actual acquisition prices. Lowering the MAC triggers another round of generic price competition as generic manufacturers seek to increase their market share by offering larger margins in pharmacies. If a Medicare RP required that RPs be fixed for a year, as proposed by Huskamp et al. (2000), more of the savings from generic competition would accrue to pharmacists rather than to payers, as in the Netherlands, and generic prices and reimbursement might decline somewhat less rapidly over time than they do currently under the more flexible MAC systems used by competing PBMs.

Assuming that a Medicare RP system would be structured to mimic roughly U.S. MAC programs for generics, this could have a devastating effect on revenues for on-patent products in the same class. For example, if generic prices are on average, say, 20 percent of originator 
prices, then the reimbursement for on-patent products would fall by 80 percent once the first molecule in the class goes off-patent. If an onpatent drug in a mixed class maintained its price, patients would face an out-of-pocket cost equal to the brand-generic price differential, which would likely be significantly higher than surcharges faced by patients in other RP countries and significantly higher than the differential surcharge on nonpreferred drugs under tiered formularies. ${ }^{28}$ Many patients would presumably ask their physicians to switch them to the off-patent generic; others might ask their physicians to seek a special exemption from the surcharge, which would entail administrative costs. If demand is sufficiently elastic, originator prices would drop to the RP. Because of either lower prices or volumes or both, onpatent originator products would experience significant loss of revenue and effective loss of patent protection once the first drug in a class went off-patent.

Thus if therapeutic RP were combined with the more competitive generic RP system in the U.S., the negative effect on revenues of onpatent drugs in mixed classes would likely be greater than in the Netherlands or New Zealand, where generic competition is weaker. Although in principle this effect of RP would apply only to the roughly 40 percent of sales accounted for by seniors, in practice private payers and Medicaid would likely demand similar prices to those obtained by Medicare. Thus, the reduction in revenues would likely apply to the entire U.S. market. Because the United States accounts for over 50 percent of global pharmaceutical revenues and a larger share of profits, the effect on incentives for R\&D could thus be significant. This significant effect of RP in mixed classes does not depend on a Medicare RP system exploiting its monopsony power. It results solely from classifying onpatent drugs with off-patent drugs in the U.S. context, in which there is aggressive generic competition as a result of the incentive structure for pharmacists.

The effect of RP in the United States on the availability of new products will also be very different from other countries' experiences. Given the dominant U.S. share of the global market, it seems likely that manufacturers would rationally choose to launch new drugs because the foregone sales from not launching would be far higher than in a small market such as New Zealand. Thus, RP applied in the United States would probably not affect the availability of new drugs that are already far along in the development process (for which most fixed costs are already sunk). By contrast, the long-term effect of RP in the United 
States on the number of new drugs developed would be far greater than in other countries. A significant reduction in expected revenues in the U.S. market would significantly reduce expected global revenues and hence reduce incentives for companies to develop new drugs. These effects might not be evident for at least 5 to 10 years, assuming that the main R\&D cuts would occur for drugs still at the preclinical or phase 1 stage, (for which significant investments must still be made). The evidence from other countries cannot inform analysis of these effects given the much larger U.S. share of global sales. If a New Zealand-style approach to obtaining price cuts were applied to onpatent classes, in addition to classifying on-patent with off-patent products, the reduction in expected returns to $R \& D$ and hence in incentives for new $R \& D$ investment could be very large.

\section{Appendix 1.1: Internal Reference Pricing, External Referencing, Price Regulation, and Formularies}

\section{Internal Reference Pricing}

Internal referencing pricing systems set a common reimbursement level for different products in a designated group, with the reference price usually based on some low price in the distribution of manufacturer prices for the group of drugs. Thus, internal reference pricing compares prices across different products within a given country; its goal is to encourage price competition among manufacturers, but prices are not regulated.

\section{External Referencing}

External referencing refers to systems that limit the price and reimbursement of a specific product in one country by referring to the price of that same product in another country. This approach limits the manufacturer's ability to price-discriminate across countries for a given product but does not directly seek to promote competition between products. External referencing is used in many countries, including Italy, Canada, Belgium, Spain, and the Netherlands the latter also uses internal referencing. ${ }^{29}$

\section{Price Regulation}

In pure price regulatory systems such as those in France or Italy, the maximum reimbursable price is also the maximum that the manufacturer can charge. This regulated price may be based on external referencing to 
foreign prices for the same drug or prices of similar products on the market. Although this latter approach resembles internal RP superficially, it differs in several important respects. First, the new drug may receive a higher reimbursement price if it can show significant therapeutic advantage over existing products. Second, the cross-product comparisons usually apply only to setting the launch price of the new drug; post-launch prices are not systematically reviewed and revised when a new product enters the class. Third, in pure price regulatory schemes, the manufacturer is not permitted to charge more than the regulated price.

\section{Formularies}

Tiered formularies used by pharmacy benefit managers (PBMs) in the United States categorize compounds by therapeutic category. Within each therapeutic category, however, the reimbursement paid to manufacturers and the copayments charged to patients can differ based on cost effectiveness and other factors that the PBM uses to classify products as generics, preferred brands, and nonpreferred brands. Corresponding copayment rates are, say, $\$ 5$ for a generic, $\$ 15$ for a preferred brand, and $\$ 30$ for a nonpreferred brand. Because PBMs can shift utilization toward preferred products, they can negotiate discounts from manufacturers in return for granting preferred status to their products. Thus, unlike RP, in a tiered formulary, different compounds within a therapeutic category are commonly reimbursed at different rates. For example, if drug A is more effective than drug B in the same class, drug A can be reimbursed at a higher price and still be on the preferred tier, provided that it is equally or more cost-effective than drug B at the higher price. The reimbursement for on-patent products in a class does not immediately fall to generic levels when the patent expires on one molecule in the class. If, say, compound B is off-patent and has generic competitors, the PBM may encourage generic substitution by paying only for the generic version of compound B or placing brand B in the nonpreferred tier with a much higher copayment. But brand A, which is still on-patent, may be on the preferred tier and receive a higher reimbursement than generic $B$ if brand A offers some advantages over generic B. Patient copayment differentials are also more open-ended under RP than in the tiered copay model.

\section{Notes}

This study was supported by a grant from Wyeth. We would like to thank IMS Health for providing the data. The views expressed are those of the authors. 
1. IMS Health (IMS) is a global market research company based in Plymouth Meeting, Pa.

2. For more detail on Germany, see Ulrich and Wille (1996); for the Netherlands, see Rigter (1994) and de Vos (1996); for New Zealand, see Kletchko, Moore, and Jones (1995) and Woodfield (2001); for analysis of reference pricing in general, see Lopez-Casasnovas and Puig-Junoy (2001), Jonsson (2001), and Danzon (2001).

3. In 1999, the pharmaceutical industry challenged the right of the BKK to set RP levels as a violation of German and European Union (EU) competition law. In 2001, the federal government assumed these functions.

4. Most generics in Germany are branded, and physicians frequently prescribe the specific brand of generic. By contrast, in the United States, generics are not branded; the pharmacist is authorized to substitute unless the physician requires the brand; and because U.S. pharmacists can profit from the margin between the reimbursement and the acquisition cost, pharmacists have strong financial incentives to substitute cheap generics, which in turn creates incentives for generic manufacturers to compete on price.

5. From 1989 to 1993, products under RP were exempt from the DM3 copayment that applied to non-RP drugs. In 1993, all drugs were subject to a DM3/5/7 copayment structure initially based on the price, later on the pack size.

6. An incentive for manufacturers to price below the RP could exist if physicians are imperfectly informed about the RP and therefore tend to choose the cheapest products to reduce the risk of a patient surcharge and, in Germany, to avoid the obligation to explain the need for a surcharged product.

7. The five criteria were (1) same mechanism of action; (2) used for the same indication, based on actual use, not the official product labeling; (3) similar route of administration (for example, parenteral forms are grouped separately from oral forms of the same compound); (4) intended for the same age group; and (5) no significant differences in clinical effects, desirable or undesirable, for all patients. This broadened the earlier definition, which permitted a separate class if the clinical differences affected only some patients.

8. To inform patients, some pharmacists reportedly simply post a notice advising that substitution will occur unless the patient requests otherwise.

9. The average is an (unweighted) average price per day at the ex-wholesaler level, using the package size with the lowest unit cost in each country, including all originator and generic products (excluding parallel imports).

10. A full analysis of the effects of RP on manufacturers would include the probability that a compound is launched; the probability that a product is reference-priced and the determination of RP level; the manufacturer's price response and patient surcharge, conditional on RP; unit sales volume and market shares; and dynamic evolution of RPs, prices, and quantities over time.

11. Parallel trade refers to arbitrage shipments by a third party (usually a wholesaler) taking advantage of differences in prices charged by the originator manufacturer for the same product sold in different countries. Such parallel trade has been explicitly authorized within the European Union (EU) for trade between EU countries but not from outside the EU. In the United States, parallel trade is precluded by traditional patent law. However, current proposals before Congress would permit importation into the United States of drugs produced in a Food and Drug Administration (FDA) approved facility in Canada or several other countries. 
12. Manufacturers might achieve a relatively high price in the Netherlands by launching new products first in the unregulated U.K. and German markets, delaying launch in the more tightly regulated markets of France and Belgium. Because the Dutch price ceilings apply throughout the life of the product, they would likely be more binding for older compounds, particularly those with generics available in the benchmark countries.

13. A formal model of the effects of RP and drug budgets is developed in Danzon and Liu (1996).

14. These spillovers apply only to originator products because generics are generally not subject to cross-national price regulation and are rarely parallel traded.

15. Our data from 1998 predate the 1999 downward revision of RP levels based on these capped prices. Following this revision, RPs may be a binding constraint for more products, leading to more clustering at the RP than we observed in our 1998 data.

16. We use the IMS therapeutic classification system, which is similar to the World Health Organization's anatomical therapeutic classification (ATC) system.

17. IMS defines a standard unit as a proxy for a dose for each formulation. For oral forms, a standard unit is one tablet or one capsule; for liquids, it is 5 milliliters, etc. Our dollar price estimates use the average exchange rates, implied by the IMS data, of DM.554 = \$1, NLG.492 = \$1, and \$NZ.557 = \$1.

18. Cox proportional hazard model estimates show that the launch hazard for a new compound in New Zealand compared to Germany became significantly lower after 1994 (Danzon and Ketcham 2004 forthcoming).

19. Two additional molecules, sotalol and fenofibrate, were approved in the United States during this time period but were in at least one of the three other countries prior to 1980 , so they were excluded from the analysis in table 1.2.

20. The price (RP) relative for each molecule is defined as the ratio of the weighted average price (RP) for the molecule in the comparison country (the Netherlands or New Zealand) relative to that molecule's price (RP) in Germany.

21. The same pattern occurs if molecules are categorized by their global launch date rather than by country-specific launch date.

22. In table 1.4, the RP for each molecule is the volume-weighted average of the packlevel RP per standard unit for all packs in the molecule in each country. The analysis is based on matching molecules, but formulations may differ across countries. The estimates may be biased for the unconditional effects of RP if, for example, more expensive formulations are less likely to be launched in New Zealand for reasons other than RP.

23. The surcharge coefficients are not exactly the difference between the price and $\mathrm{RP}$ coefficients because we use the log transformation of price and RP, which are approximately log normal, whereas surcharge is in dollar units because it can be negative.

24. While our proxy for molecule efficacy is its Global age, the regime indicators are based on the Country-specific age.

25. All equations include indicator variables to identify products for which there was imputation of the subsidy because of imperfect matching of our price and subsidy data sets. 
26. RP requires the patient to pay 100 percent of the price differential of the new drug compared to the older, cheaper drug, whereas under a fixed percentage co-insurance of, say, 20 percent, the patient would pay only 20 percent of the price differential of the newer drug. Under the typical PBM formulary structure, the patient pays a tiered copayment, say, \$5 for a generic, \$15 for a preferred brand, and \$30 for a nonpreferred brand. Consider a class with three products: a generic, an originator product in molecule A that is off-patent, and an originator product in molecule B that is on-patent. A typical formulary would place off-patent originator A on the nonpreferred tier, and generic $\mathrm{A}$ and originator B on the preferred tier. A patient who wants originator A must pay the full originator price differential of brand A relative to generic A. For on-patent originator B, however, the out-of-pocket price to the patient is only $\$ 15$ and the PBM pays the manufacturer price minus the $\$ 15$ and minus any discounts negotiated by the manufacturer to get the preferred tier placement.

27. The evidence suggests that price competition among on-patent, therapeutic substitute products is fairly weak in the absence of management by a PBM, possibly because unmanaged drug demand is dominated by physicians, who are not highly price-sensitive. If the Medicare drug benefit uses the proposed 25 percent co-insurance rate, this might induce more price sensitivity in patients and physician-agents and hence more price competition. Still, it seems likely that using a tiered formulary, with its leverage to negotiate discounts on on-patent drugs, would offer seniors a better trade-off between out-of-pocket exposure and choice of drug than would an RP system.

28. Brand-generic price differentials are significantly higher in the United States than in most other countries because the United States has both relatively low generic prices and relative high originator prices (Danzon and Furukawa 2003).

29. External referencing is discussed in Danzon (1997).

\section{References}

Danzon, P. M. (1997). "Price Discrimination for Pharmaceuticals: Welfare Effects in the US and the EU," International Journal of the Economics of Business, 4:301-321.

Danzon, P. M. (2001). "Reference Pricing: Theory and Evidence," in G. LopezCasasnovas and B. Jonsson (eds.), Reference Pricing and Pharmaceutical Policy. New York: Springer.

Danzon, P. M., and L. Chao (2000). “Cross-National Price Differences for Pharmaceuticals: How Large, and Why?" Journal of Health Economics, 19:159-195.

Danzon, P. M., and M. Furukawa (2003). “Cross-National Price Differences for Pharmaceuticals: Evidence from Nine Countries." Health Affairs.

Danzon, P. M., and J. Ketcham (2004 forthcoming). "The Effects of Reference Pricing on Prices, Availability and Utilization of Pharmaceuticals," The Wharton School, University of Pennsylvania, working paper.

Danzon, P. M., and H. Liu. (1996). "Reference Pricing and Physician Drug Budgets: The German Experience in Controlling Pharmaceutical Expenditures," University of Pennsylvania, working paper. 
Danzon, P. M., Y. R. Wang, and L. Wang (2002). "The Impact of Price Regulation on the Launch Delay of New Drugs-Evidence from Twenty-Five Major Markets in the 1990s," NBER working paper no. 9874.

de Vos, C. (1996). "The 1996 Pricing and Reimbursement Policy in the Netherlands," PharmacoEconomics, 10Suppl2:75-80.

Huskamp, H. A., M. B. Rosenthal, R. G. Frank, and J. P. Newhouse (2000). “The Medicare Prescription Drug Program: How Will the Game Be Played?" Health Affairs, 19(2):18-23.

Ioannides-Demos, L. L., J. E. Ibrahim, and J. J. McNeil (2002). “Reference-Based Pricing Schemes: Effect on Pharmaceutical Expenditure, Resource Utilisation and Health Outcomes," PharmacoEconomics, 20(9):577-591.

Jonsson, B. (2001). "Reference Pricing: Central Economic Issues," in G. LopezCasasnovas and B. Jonsson (eds.), Reference Pricing and Pharmaceutical Policy. New York: Springer.

Kanavos, P., and U. Reinhardt (2003). "Reference Pricing For Drugs: Is It Compatible With U.S. Health Care?" Health Affairs 22:16-31.

Kletchko, S. L., D. W. Moore, and K. L. Jones (1995). “Targeting Medicines: Rationalising Resources in New Zealand." Wellington, New Zealand: Pharmac.

Lopez-Casasnovas, G., and J. Puig-Junoy (2001). "Review of the Literature on Reference Pricing," in G. Lopez-Casasnovas and B. Jonsson (eds.), Reference Pricing and Pharmaceutical Policy. New York: Springer.

Kanavos, P., and U. Reinhardt (2003). "Reference Pricing for Drugs: Is It Compatible with U.S. Health Care?" Health Affairs, 22(3):16-30.

Ma, C. T., and M. H. Riordan (2002). "Insurance, Moral Hazard, and Managed Care," Journal of Economics \& Management Strategy 11(1):81-108.

Maasen, B. M. (1995). Reimbursement of Medicinal Products: The German Reference Price System. Law, Administrative Practice and Economics. Zellik, Belgium: Center for New Europe.

Merck Frosst Canada (1996). Policy Paper on Health Care Cost Containment. Vancouver, Canada.

Morton, F. S. (1997). "The Strategic Response of Pharmaceutical Firms to the Medicaid Most-Favored-Customer Rules," Rand Journal of Economics, 28(2):269-290.

Pauly, M. V. (1968). "The Economics of Moral Hazard: Comment (in Communications)," The American Economic Review, 58(3):531-537.

Pavcnik, N. (2002). "Do Pharmaceutical Prices Respond to Patient Out-of-Pocket Expenses?" Rand Journal of Economics, 33(autumn):469-487.

Pharma Pricing Review (1996).

Remit Consultants (1991). Cost Containment in the European Pharmaceutical Market: New Approaches. London: Remit Consultants.

Rigter, H. (1994). "Recent Public Policies in the Netherlands to Control Pharmaceutical Pricing and Reimbursement," PharmacoEconomics, 6(Suppl1):15-24. 
Sanders, J. (2001). "Pharmaceutical Reference Pricing," presentation, Advance PCS, ISPOR Conference, May.

Schneeweiss, S., S. B. Soumerai, R. J. McGlynn, M. MacClure, C. Dormuth, and A. M. Walker (2002). "The Impact of Reference-Based Pricing for Angiotensin-Converting Enzyme Converting Inhibitors on Drug Utilization," Canadian Medical Association Journal, 166(6):737-745.

Schoffski, O. (1996). “Consequences of Implementing a Drug Budget for Office-Based Physicians in Germany," PharmacoEconomics, 10 (Suppl2)81-88.

Thomas, M. C., J. Mann, and S. Williams (1998). “The Impact of Reference Pricing on Clinical Lipid Control," New Zealand Medical Journal, 111:292-294.

Ulrich, V., and E. Wille (1996). "Health Care Reform and Expenditure on Drugs," PharmacoEconomics, 10 (Suppl2):81-88.

VFA (Verband Forschender Arzneimittelhersteller) (2000). Statistics2000. Berlin, Germany: Verband Forschender Arzneimittelhersteller.

Woodfield, A. (2001). "Theory and Evidence from New Zealand," in G. LopezCasasnovas and B. Jonsson (eds.)., Reference Pricing and Pharmaceutical Policy. New York: Springer.

Zeckhauser, R. J. (1970). "Medical Insurance: A Case Study of the Tradeoff between Risk Spreading and Appropriate Incentives," Journal of Economic Theory, 2(1):10-26. 